\title{
Effect of sodium bicarbonate contribution on energy metabolism during exercise: a systematic review and meta-analysis
}

Jorge Lorenzo Calvo ${ }^{1 *}$, Huanteng X $\mathrm{u}^{2^{*}} \mathbb{D}$, Daniel Mon-López ${ }^{1}$, Helios Pareja-Galeano ${ }^{2}$ and Sergio Lorenzo Jiménez ${ }^{3}$

\begin{abstract}
Background: The effects of sodium bicarbonate $\left(\mathrm{NaHCO}_{3}\right)$ on anaerobic and aerobic capacity are commonly acknowledged as unclear due to the contrasting evidence thus, the present study analyzes the contribution of $\mathrm{NaHCO}_{3}$ to energy metabolism during exercise.

Methods: Following a search through five databases, 17 studies were found to meet the inclusion criteria. Metaanalyses of standardized mean differences (SMDs) were performed using a random-effects model to determine the effects of $\mathrm{NaHCO}_{3}$ supplementation on energy metabolism. Subgroup meta-analyses were conducted for the anaerobic-based exercise (assessed by changes in $\mathrm{pH}$, bicarbonate ion $\left[\mathrm{HCO}_{3}{ }^{-}\right]$, base excess [BE] and blood lactate [BLa]) vs. aerobic-based exercise (assessed by changes in oxygen uptake $\left[\mathrm{VO}_{2}\right]$, carbon dioxide production $\left[\mathrm{VCO}_{2}\right]$, partial pressure of oxygen $\left[\mathrm{PO}_{2}\right]$ and partial pressure of carbon dioxide $\left[\mathrm{PCO}_{2}\right]$ ).

Results: The meta-analysis indicated that $\mathrm{NaHCO}_{3}$ ingestion improves $\mathrm{pH}(\mathrm{SMD}=1.38,95 \% \mathrm{Cl}: 0.97$ to 1.79, $P<0.001$; $\left.\mathrm{I}^{2}=69 \%\right), \mathrm{HCO}_{3}{ }^{-}\left(\mathrm{SMD}=1.63,95 \% \mathrm{Cl}: 1.10\right.$ to $\left.2.17, P<0.001 ; \mathrm{I}^{2}=80 \%\right), \mathrm{BE}(\mathrm{SMD}=1.67,95 \% \mathrm{Cl}: 1.16$ to $2.19, P<0.001$, $\left.I^{2}=77 \%\right)$, BLa (SMD $=0.72,95 \% \mathrm{Cl}: 0.34$ to $\left.1.11, P<0.001, I^{2}=68 \%\right)$ and $\mathrm{PCO}_{2}(\mathrm{SMD}=0.51,95 \% \mathrm{Cl}: 0.13$ to $0.90, P=$ $0.009, \mathrm{I}^{2}=0 \%$ ) but there were no differences between $\mathrm{VO}_{2}, \mathrm{VCO}_{2}$ and $\mathrm{PO}_{2}$ compared with the placebo condition.

Conclusions: This meta-analysis has found that the anaerobic metabolism system (AnMS), especially the glycolytic but not the oxidative system during exercise is affected by ingestion of $\mathrm{NaHCO}_{3}$. The ideal way is to ingest it is in a gelatin capsule in the acute mode and to use a dose of $0.3 \mathrm{~g} \cdot \mathrm{kg}^{-1}$ body mass of $\mathrm{NaHCO}_{3} 90$ min before the exercise in which energy is supplied by the glycolytic system.
\end{abstract}

Keywords: Sodium bicarbonate, Energy metabolism, exercise, Aerobic-based, Anaerobic-based

\footnotetext{
* Correspondence: jorge.lorenzo@upm.es; xht-hunter@bsu.edu.cn

${ }^{1}$ Faculty of Physical Activity and Sport science, Universidad Politécnica de

Madrid, Madrid, Spain

${ }^{2}$ Faculty of Sport Sciences, Universidad Europea de Madrid, Madrid, Spain

Full list of author information is available at the end of the article
}

(c) The Author(s). 2021 Open Access This article is licensed under a Creative Commons Attribution 4.0 International License, which permits use, sharing, adaptation, distribution and reproduction in any medium or format, as long as you give appropriate credit to the original author(s) and the source, provide a link to the Creative Commons licence, and indicate if changes were made. The images or other third party material in this article are included in the article's Creative Commons licence, unless indicated otherwise in a credit line to the material. If material is not included in the article's Creative Commons licence and your intended use is not permitted by statutory regulation or exceeds the permitted use, you will need to obtain permission directly from the copyright holder. To view a copy of this licence, visit http://creativecommons.org/licenses/by/4.0/ The Creative Commons Public Domain Dedication waiver (http://creativecommons.org/publicdomain/zero/1.0/) applies to the data made available in this article, unless otherwise stated in a credit line to the data. 


\section{Background}

Energy supply is an important prerequisite for maintaining exercise, in which fat, carbohydrate (glucose) and protein are converted into adenosine triphosphate (ATP) to provide energy for the body. Energy output from human movement is divided between anaerobic and aerobic energy supply systems. The anaerobic systems are the phosphagen system and glycolytic system, which synthesize ATP without oxygen participation. The energy supply substrates of the phosphagen system are ATP and creatine phosphate (CP or phosphocreatine $[\mathrm{PCr}])$, also called the ATP-CP system. ATP-CP participates in energy supply directly, which is the fastest but also shortest way to maintain the duration of the energy supply. The energy substrate of the glycolytic system is glucose, which synthesizes ATP by decomposing glucose. The process by which the body decomposes a substrate under aerobic conditions is called intracellular respiration. This process requires the participation of oxygen, and is called the oxidative system. The mitochondria in the cells are the organs that produce ATP by glucose, fat and protein oxidation, and at the same time, the cardiovascular and respiratory systems need to transport large amounts of oxygen to the muscles for their needs [1], (Table 1).

In exercise physiology the interconnection between the energy required to complete different types of exercise and the ways supplied by each energy system together is referred to as the Continuous unity of energy (CUE) [2]. It describes the corresponding overall relationship between different movements and different energy supply paths of the energy system (Unity of sport and energy supply). The CUE is generally expressed as the percentage of aerobic and anaerobic energy supplied. According to the ratio of anaerobic and aerobic energy supplied for different sports, the relative positions of various sports in the CUE can be determined and the sport can be understood by what is the leading energy supply system.

The ratio of the anaerobic and aerobic energy supply is determined by exercise intensity. The ATP-CP system mainly provides energy for high-intensity short-term exercise (i.e., sprinting, throwing, jumping and weight lifting); the glycolytic system mainly provides energy for medium-high-intensity, short-term exercise (i.e., $400 \mathrm{~m}$ running and $100 \mathrm{~m}$ swimming) and the oxidative system mainly functions for low-medium-intensity, mediumlong time exercise (i.e., long distance running, rowing and cycling), (Table 2). The energy supply capacity of different energy systems determines the strength of exercise capacity.

The ATP-CP system tells us that when ATP is used, creatine kinase decomposes $\mathrm{PCr}$ and simultaneously removes inorganic phosphate $(\mathrm{Pi})$ to release energy during explosive activities [3]. The energy generated when decomposing $\mathrm{PCr}$ can combine $\mathrm{Pi}$ with adenosine diphosphate (ADP) to regenerate ATP, thereby maintaining the stability of ATP levels. The principle of the glycolytic system is that glycogen or glucose decomposes to form pyruvate, which becomes lactic acid in the absence of oxygen. If lactic acid is not removed in time, it will be decomposed and converted into lactate and cause a large amount of $\mathrm{H}^{+}$ accumulation, resulting in muscle acidification, causing acidosis [4].

The increase of $\mathrm{H}^{+}$will cause decreases of $\mathrm{pH}$ in the body, and the destroyed acid-base balance will damage muscle contractility and hinder ATP production. In order to reduce the effect of free $\mathrm{H}^{+}$, alkaline substances in blood and muscle will combine with $\mathrm{H}^{+}$to buffer or neutralize it [5]. In the body, there are three main chemical buffers, bicarbonate ions $\left(\mathrm{HCO}_{3}{ }^{-}\right), \mathrm{Pi}$, and protein. In addition, the hemoglobin in red blood cells is also an important buffer, but a large part depends on $\mathrm{HCO}_{3}{ }^{-}$ (see Table 3) [1]. When lactic acid is formed, the body's fluid buffer system will increase the $\mathrm{HCO}_{3}{ }^{-}$in the blood to help the body quickly recover from fatigue. This process is called bicarbonate loading [6]. Sodium bicarbonate $\left(\mathrm{NaHCO}_{3}\right)$ is a type of physiological supplement. Ingesting some substances that can increase the $\mathrm{HCO}_{3}{ }^{-}$ in the blood, like $\mathrm{NaHCO}_{3}$, can increase the blood $\mathrm{pH}$ and make it more alkaline. The higher the $\mathrm{HCO}_{3}{ }^{-}$, the stronger the acid-base buffer provided, allowing higher concentrations of lactic acid in the blood.

There are some studies showing that $\mathrm{NaHCO}_{3}$ can change the content of blood lactate (BLa), $\mathrm{HCO}_{3}{ }^{-}, \mathrm{pH}$ and $\mathrm{BE}$ [7-10] during anaerobic-based exercise. Although those parameters are affected by ingesting $\mathrm{NaHCO}_{3}$, the

Table 1 The basic characteristics of the three energy supply systems

\begin{tabular}{llll}
\hline $\begin{array}{l}\text { Name of energy } \\
\text { supply system }\end{array}$ & Energy substrate & $\begin{array}{l}\text { Available } \\
\text { exercise time }\end{array}$ & $\begin{array}{l}\text { Supply substances and } \\
\text { metabolites for ATP recovery }\end{array}$ \\
\hline ATP-CP & ATP & $6 \sim 8 \mathrm{~s}$ & $\mathrm{CP}$ \\
& CP & $<10 \mathrm{~s}+\mathrm{ADP} \rightarrow \mathrm{ATP}+\mathrm{C}$ \\
Glycolytic system & Glucose & $2 \sim 3 \mathrm{~min}$ & $\mathrm{Glucose} \rightarrow \mathrm{Lactic}$ acid \\
Oxidative system & Glucose & $3 \sim 5 \mathrm{~min}$ & $\mathrm{Glucose} \rightarrow \mathrm{CO}_{2}+\mathrm{H}_{2} \mathrm{O}$ \\
& Fat & $1 \sim 2 \mathrm{~h}$ & Fat $\rightarrow \mathrm{CO}_{2}+\mathrm{H}_{2} \mathrm{O}$ \\
\hline
\end{tabular}


Table $\mathbf{2}$ Corresponding position of sports in the CUE

\begin{tabular}{llll}
\hline Sports & Aerobic (\%) & Anaerobic (\%) & Sports \\
\hline Weight lifting, diving, gymnastics & 0 & 100 & $100 \mathrm{~m}$ running, \\
& & & Golf and tennis swing \\
$200 \mathrm{~m}$ running, wrestling, & 10 & 90 & Soccer, basketball, baseball, \\
Ice hockey & 20 & 80 & Volleyball, $500 \mathrm{~m}$ skiing, $400 \mathrm{~m}$ running \\
Tennis, lawn hockey & 30 & 70 & Lacrosse \\
$800 \mathrm{~m}$ running, boxing & 40 & 60 & $200 \mathrm{~m}$ swimming, \\
& 50 & 50 & 1500 m skating \\
2000 m rowing & 60 & 40 & $1500 \mathrm{~m}$ running \\
1500 m running, & 70 & 30 & $800 \mathrm{~m}$ swimming \\
$400 \mathrm{~m}$ swimming & & & Trail running \\
3000 m running & 80 & 20 & Cross country skiing, jogging \\
5000 m running, & 90 & 10 & \\
10,000 m skating, & 100 & 0 &
\end{tabular}

change of anaerobic metabolism systems (AnMS) is different. The capacity of the glycolytic system could increase [11] or stay the same [12], but the ATP-CP system seems not affected by ingestion of $\mathrm{NaHCO}_{3}$, because the ATP or $\mathrm{PCr}$ content is not affected by $\mathrm{NaHCO}_{3}[12,13]$. Due to the participation of oxygen in the process of ATP synthesis in the oxidative system, a large number of studies have shown that enhancing oxygen uptake and the muscle's ability to use oxygen can improve the oxidative system capacity. For that reason, some researchers explored whether $\mathrm{NaHCO}_{3}$ will increase oxygen uptake and affect the oxidative system. Similar to the glycolytic system, contradictory evidence is shown in the existing literature, demonstrating that the capacity of the glycolytic system could increase [14] or stay the same with $\mathrm{NaHCO}_{3}$ ingestion [15].

The main reason why $\mathrm{NaHCO}_{3}$ has different effects on different energy metabolism systems may be due to the different exercise durations reflected by different exercise types. Some studies have shown that an intake of $\mathrm{NaHCO}_{3}$ will improve high-intensity intermittent exercise $[16,17]$ or repeat sprint ability $[18,19]$. According to the exercise duration reflected by the specific sport characteristics, some scholars have concluded that $\mathrm{NaHCO}_{3}$ has an effect on exercises of less than $4 \mathrm{~min}$,

Table 3 Buffer capacity of blood components

\begin{tabular}{lll}
\hline Buffers & Slykes* & $\%$ \\
\hline $\mathrm{HCO}_{3}{ }^{-}$ & 18.0 & 64 \\
Hemoglobin & 8.0 & 29 \\
Protein & 1.7 & 6 \\
$\mathrm{Pi}$ & 0.3 & 1 \\
Total & 28.0 & 100 \\
\hline
\end{tabular}

Note: * refers to the $\mathrm{pH}$ value per liter of blood ranging from 7.4 to 7.0 , which can neutralize the milliequivalent of $\mathrm{H}^{+}$ but no effect on exercise of a longer duration [20]. Other scholars have found a more specific time effect, that for less than $1 \mathrm{~min}$ or more than $7 \mathrm{~min}$ it is ineffective and its supplementary benefits for anaerobic exercise within $2 \mathrm{~min}$ are very limited [1]. Another point is the gender difference, that men seem to benefit more from the supplementation of $\mathrm{NaHCO}_{3}[19,21]$, the reason for which might be found in physiological differences. Women have smaller type II fibers than men, and type II fibers rely predominantly on the glycolytic energy system [22] This may explain why the previous research has contradictory results.

Unlike previous studies, due to different results and study discussions, this review no longer focuses on specific sports, exercise tasks or duration, but instead goes back to its source to explore the mechanism and principles of application of $\mathrm{NaHCO}_{3}$. Despite all apparent changes, the energy supply is essentially the same in all sports.

Knowledge of nutrition can influence dietary choices and impact athletic performance, and is important for coaches because they are often the most significant source of such knowledge for their athletes [23]. In addition, one article concluded that the level of athletes' knowledge about the proper and intended use of sports supplements reveals the necessity of enforcing ongoing education about sports supplementation [24]. Clarifying the role of $\mathrm{NaHCO}_{3}$ can provide a reference for a lot of athletes and coaches.

\section{Materials and methods} Search strategy

The present article is a meta-analysis focusing on the contribution of sodium bicarbonate to energy metabolism during different types of exercise (i.e., aerobic-based and anaerobic-based). This study followed the Preferred 
Reporting Elements for Systematic Reviews and Metaanalysis (PRISMA) guidelines [25] and the eligibility criteria of articles was determined with the application of the Participants, Intervention, Comparison, Outcome and Study design (PICOS) question model [26], elements were used in title, abstract and/or full text of articles to identity studies that met the eligibility criteria (Table 4).

A systematic search was conducted using PubMed, Web of Science, SCOPUS, Medline and SPORTDiscus databases to identify eligible studies published from 2010 to June 2020. Search terms related with main concepts were used: "sodium bicarbonate" AND ("metabolism" OR "energy expenditure") AND ("exercise" OR "physical activity" OR "sport") AND "aerobic" AND "anaerobic". Through this search, a total of 351 articles were obtained and 17 articles were finally included in this meta-analysis.

\section{Selection of articles: inclusion and exclusion criteria}

After obtaining the 351 articles according to the inclusion criteria of PICOS in the search, the following exclusion criteria were taken into consideration to determine the final studies: 1) Review and meta-analysis; 2) No sodium bicarbonate supplement ingestion or the outcomes measure not related to energy metabolism; 3) Supplement mixed with other supplements (i.e. caffeine or beta-alanine); 4) Animal experiments; 5) Injury participants or without training experience; 6) Study design not matched: not under the same experimental conditions (i.e., Hypoxia or ingested after high intensity exercise), without exercise after ingesting, no placebo as a comparison group; 7) Inadequate parameter measurement; 8) Data not described in detail (e.g., no mean or standard deviation (SD), no response after emailing author). The data collection process is presented in Fig. 1.

The methodological quality of the articles, was evaluated using McMaster's Critical Review Form [27]. The McMaster Form contains 15 items that are scored depending on the degree to which the specific criteria were met (yes $=1$, no $=0$ ). A summary score was calculated for each article by summing the total score

Table 4 PICOS (Participants, Intervention, Comparison, Outcomes and Study design)

\begin{tabular}{|c|c|}
\hline $\begin{array}{l}\text { PICOS } \\
\text { components }\end{array}$ & Detail \\
\hline Participants & Healthy exercise adults \\
\hline Intervention & Supplementation with $\mathrm{NaHCO}_{3}$ \\
\hline Comparison & Same conditions with placebo or control group \\
\hline Outcomes & $\begin{array}{l}\text { Changes in some parameters that can express } \\
\text { changes in energy metabolism (i.e., } \mathrm{HCO}_{3}^{-}, \mathrm{pH}, \mathrm{BE} \text {, } \\
\mathrm{BLa}_{1} \mathrm{VO}_{2}, \mathrm{CO}_{2}, \mathrm{PO}_{2} \text { and } \mathrm{PCO}_{2} \text { ) }\end{array}$ \\
\hline Study design & $\begin{array}{l}\text { Crossover or counterbalanced double- or single-blind, } \\
\text { randomized controlled trials }\end{array}$ \\
\hline
\end{tabular}

obtained across relevant items and dividing it by the total possible score. The evaluation score of the quality of the articles is shown in Table 5. The main deficiencies found in methodological quality are associated with item 14 of the questionnaire, which is "were drop-outs reported?", as there is no description about whether participants dropped out or not.

\section{Data extraction and analysis}

Physiological results data were extracted in the form of mean, SD, and sample size for placebo and $\mathrm{NaHCO}_{3}$ cohorts. Data were collected directly from tables or within text of the selected studies when possible. Data of 6 studies were partially abstracted by online graph digitizing software (WebPloDigitizer ${ }^{1}$ ) when values were not reported in the text. This included values abstracted directly with mean and SD [28-30] or calculated after obtaining mean and standard error (SE) [31, 32] or a 95\% confidence interval (95\% CI) [33]. A study was excluded from the meta-analysis when the missing data could not be provided, or the author did not respond [34-36]. Dependent variables include those parameters relevant to energy metabolism after exercises following the supplement intervention. When pertinent data were not available or referenced in the article, the study was excluded from the meta-analysis.

The meta-analysis was conducted using the Review Manager 5.3 (v5.3, Cochrane Collaboration, Copenhagen, Denmark, 2020) in order to aggregate, via a random-effects model [37], the standardized mean difference (SMD) between the effects of $\mathrm{NaHCO}_{3}$ and placebo cohorts. The mean \pm SD and sample size were used to calculate SMD. A sub-group analysis was also performed to evaluate the influence on exercise with different metabolic characteristics. The use of the SMD summary statistic allowed all effect sizes to be transformed into a uniform scale, which was interpreted, according to Cohen's conventional criteria [38], with SMD of $<0.20$ being classified as negligible, $0.20-0.49$ classified as small; $0.50-0.79$ classified as moderate; and > 0.80 classified as large. Heterogeneity was determined using $\mathrm{I}^{2}$ value, with values of 25,50 and 75 indicating low, moderate and high heterogeneity, respectively. The results are reported as weighted means and 95\% CI. The statistical significance was set at $p<0.05$.

\section{Results \\ Study selection and characteristics}

A total of 351 articles were initially identified through databases. Of the 186 that remained after the removal of 165 duplicates, 101 articles were not considered relevant and were excluded. Based on the inclusion criteria, 17 articles, published between 2010 and 2019, met the full

\footnotetext{
${ }^{1}$ https://apps.automeris.io/wpd/index.zh_CN.html
} 


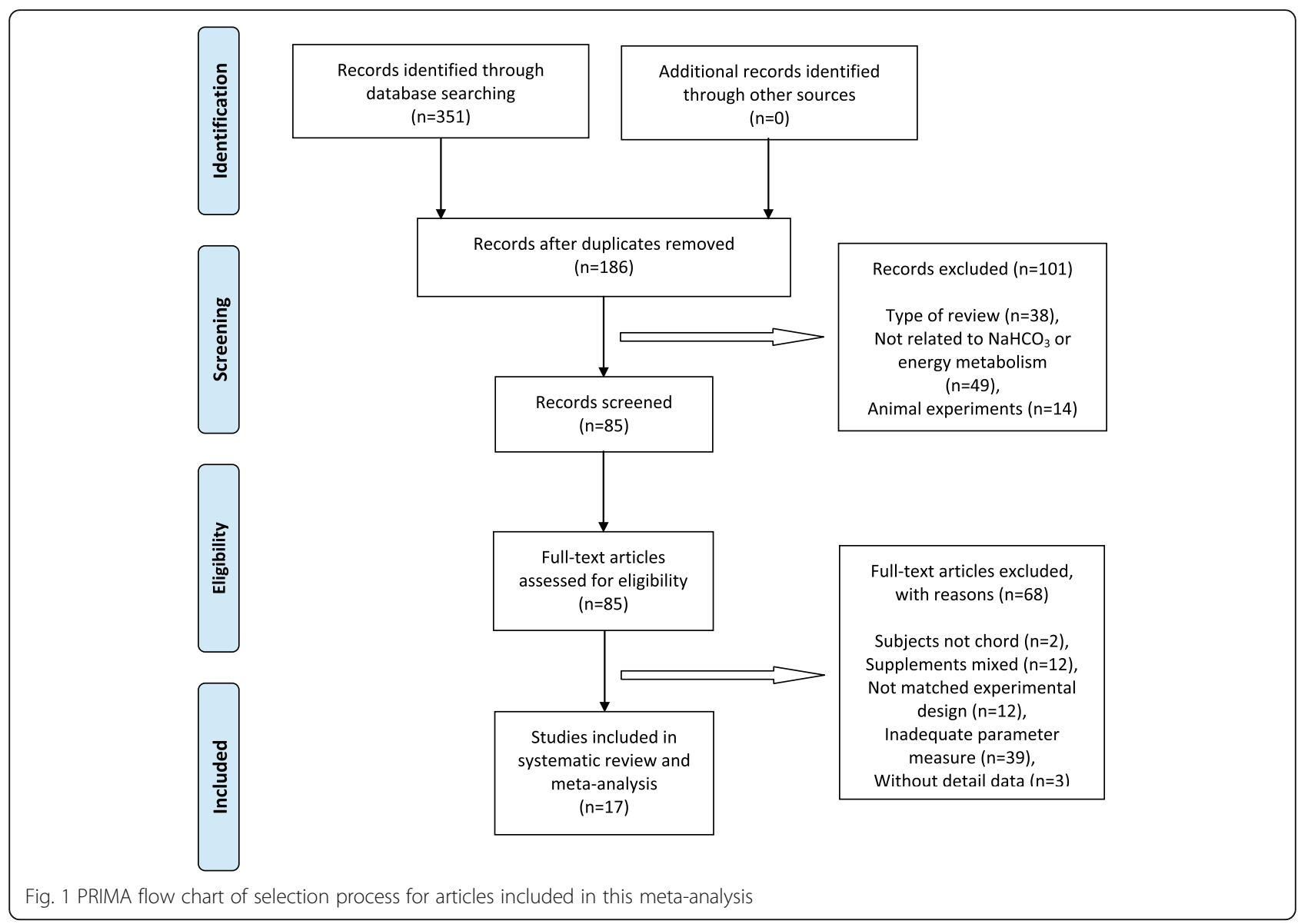

set of criteria and were included for review. All descriptions and characteristics of the review studies are presented in Tables 6 and 7. Moreover, the quality assessment of selected articles was classified as Very Good (Table 5).

The study design, testing parameters and participants' characteristics for the meta-analyzed studies are displayed in Tables 6 and 7. All studies are divided into two types of exercise, either anaerobic-based or aerobic-based. Exercise characteristics depend on the experimental design after $\mathrm{NaHCO}_{3}$ intervention in these studies, which is whether the exercise is dominated by anaerobic or aerobic ability. After review, 11 articles [28, 29, 31-33, 39-44] were found to belong to anaerobic-based exercise for analysis of AnMS, which are the ATP-CP and glycolytic systems), and 6 articles $[30,45-49]$ were found to belong to aerobic-based exercise for analysis of the oxidative system.

The total number of participants across all studies was 215. Studies either used mixed-sex samples (3 studies) or included only men (10 studies) or only women (1 study) and another 3 studies did not describe the gender of sample subjects. Out of the 17 included studies, 14 used a $\mathrm{NaHCO}_{3}$ dose of $0.3 \mathrm{~g} \bullet \mathrm{kg}^{-1}$, two studies used the dose of $0.5 \mathrm{~g} \cdot \mathrm{kg}^{-1}$, and one study used the dose of 4 mmol $\cdot \mathrm{kg}^{-1}$ (about $0.336 \mathrm{~g} \cdot \mathrm{kg}^{-1}$ ). The timing of ingestion ranged from $60 \mathrm{~min}$ up to $4 \mathrm{~h}$ pre-exercise. In some studies, the dose of $\mathrm{NaHCO}_{3}$ was provided at one timepoint, with other studies splitting up the total dose at multiple timepoints. The duration of $\mathrm{NaHCO}_{3}$ administration was either once or on 5 consecutive days. The type of administration was via gelatin capsules or tablets, but some studies did not report this information (Tables 6 and 7).

\section{The influence after ingesting $\mathrm{NaHCO}_{3}$ on AnMS}

Metabolic by-products (e.g., lactic acid) are largely accumulated following the AnMS energy generation process. In the process of dissociating the metabolic by-product, the concentration of $\mathrm{H}^{+}$in body fluids will increase and therefore lower the $\mathrm{pH}$ value. In order to reduce the effect of free $\mathrm{H}^{+}$, the alkaline substances in blood and muscle will combine with $\mathrm{H}^{+}$to buffer or neutralize $\mathrm{H}^{+}$.

Fortunately, cells and body fluids have buffers such as $\mathrm{HCO}_{3}{ }^{-}$, that can reduce the impact of $\mathrm{H}^{+}$. Without the buffers, $\mathrm{H}^{+}$would lower the body's $\mathrm{pH}$ value by 1.5 , resulting in cell death. When the intracellular $\mathrm{pH}$ value is lower than 6.9, it inhibits the activity of important glycolytic enzymes and reduces the rate of glycolytic and ATP production. When the $\mathrm{pH}$ value reaches $6.4, \mathrm{H}^{+}$ 
Table 5 Methodological quality of the studies included in this meta-analysis [27]

\begin{tabular}{|c|c|c|c|c|c|c|c|c|c|c|c|c|c|c|c|c|c|c|c|}
\hline & Items & 1 & 2 & 3 & 4 & 5 & 6 & 7 & 8 & 9 & 10 & 11 & 12 & 13 & 14 & 15 & $T(s)$ & $\%$ & MQ \\
\hline \multirow[t]{17}{*}{ References } & [33] & 1 & 1 & 1 & 1 & 1 & 1 & 1 & 1 & 1 & 1 & 1 & 1 & 1 & 0 & 1 & 14 & 93.3 & $\overline{V G}$ \\
\hline & [29] & 1 & 1 & 1 & 1 & 1 & 1 & 1 & 1 & 1 & 1 & 1 & 1 & 1 & 1 & 1 & 15 & 100 & E \\
\hline & [39] & 1 & 1 & 1 & 1 & 1 & 1 & 1 & 1 & 1 & 1 & 1 & 1 & 1 & 1 & 1 & 1 & 100 & E \\
\hline & [28] & 1 & 1 & 1 & 1 & 1 & 1 & 1 & 1 & 1 & 1 & 1 & 1 & 1 & 0 & 1 & 14 & 93.3 & VG \\
\hline & [40] & 1 & 1 & 1 & 1 & 1 & 1 & 1 & 1 & 1 & 1 & 1 & 1 & 1 & 1 & 1 & 15 & 100 & E \\
\hline & [41] & 1 & 1 & 1 & 1 & 1 & 1 & 1 & 1 & 1 & 1 & 1 & 1 & 1 & 0 & 1 & 14 & 93.3 & VG \\
\hline & [42] & 1 & 1 & 1 & 1 & 1 & 1 & 1 & 1 & 1 & 1 & 1 & 1 & 1 & 0 & 1 & 14 & 93.3 & VG \\
\hline & [43] & 1 & 1 & 1 & 1 & 1 & 1 & 1 & 1 & 0 & 1 & 1 & 1 & 1 & 0 & 1 & 13 & 86.7 & $V G$ \\
\hline & [32] & 1 & 1 & 1 & 1 & 1 & 1 & 1 & 1 & 1 & 1 & 1 & 1 & 1 & 0 & 1 & 14 & 93.3 & VG \\
\hline & [31] & 1 & 1 & 1 & 1 & 1 & 1 & 1 & 1 & 1 & 1 & 1 & 1 & 1 & 0 & 1 & 14 & 93.3 & VG \\
\hline & [44] & 1 & 1 & 1 & 1 & 1 & 1 & 1 & 1 & 1 & 1 & 1 & 1 & 1 & 0 & 1 & 14 & 93.3 & VG \\
\hline & [45] & 1 & 1 & 1 & 1 & 1 & 1 & 1 & 1 & 1 & 1 & 1 & 1 & 1 & 0 & 1 & 14 & 93.3 & $V G$ \\
\hline & [46] & 1 & 1 & 1 & 1 & 1 & 1 & 1 & 1 & 1 & 1 & 1 & 1 & 1 & 1 & 1 & 15 & 100 & E \\
\hline & [30] & 1 & 1 & 1 & 1 & 1 & 1 & 1 & 1 & 1 & 1 & 1 & 1 & 1 & 1 & 1 & 15 & 100 & E \\
\hline & [47] & 1 & 1 & 1 & 1 & 1 & 1 & 1 & 1 & 1 & 1 & 1 & 1 & 1 & 1 & 1 & 15 & 100 & E \\
\hline & [48] & 1 & 1 & 1 & 1 & 1 & 1 & 1 & 1 & 1 & 1 & 1 & 1 & 1 & 0 & 1 & 14 & 93.3 & VG \\
\hline & [49] & 1 & 1 & 1 & 1 & 1 & 1 & 1 & 1 & 1 & 1 & 1 & 1 & 1 & 1 & 1 & 14 & 93.3 & VG \\
\hline $\mathrm{T}(\mathrm{i})$ & & 17 & 17 & 17 & 17 & 17 & 17 & 17 & 17 & 16 & 17 & 17 & 17 & 17 & 6 & 17 & & $M=95.28$ & \\
\hline
\end{tabular}

T(s): Total items fulfilled by study. (1) Criterion met; (0) Criterion not met. T(i): Total items fulfilled by items. Methodological Quality (MQ): poor (P) $\leq 8$ points; acceptable (A) 9-10 points; good (G) 11-12 points; very good (VG) 13-14 points; excellent (E) =15 points. M refers to mean

will stop any further decomposition of glycogen, causing ATP to rapidly decline until the end of the failure. However, due to the body's buffering capacity, even during the most strenuous exercise, the concentration of $\mathrm{H}^{+}$ can be maintained at a very low level. Even when exhausted, the muscle $\mathrm{pH}$ value drops slightly from the steady state of $\mathrm{pH} 7.1$, but it will not drop to a $\mathrm{pH}$ below 6.6-6.4 [1].

To sum up, ingesting $\mathrm{NaHCO}_{3}$ will neutralize $\mathrm{H}^{+}$, thus affecting the content of buffer substances $\left(\mathrm{HCO}_{3}{ }^{-}\right)$in the body and $\mathrm{pH}$, thereby affecting the body's acid-base balance. Since ingestion of $\mathrm{NaHCO}_{3}$ leads to a higher efflux of lactate from the working skeletal muscle to the plasma, BLa can reflect metabolic ability to a certain extent. Therefore, the four variables (i.e., $\mathrm{HCO}_{3}{ }^{-}, \mathrm{pH}, \mathrm{BE}$ and BLa), at the last time point (i.e., the influence after the last exercise if it has two or more bouts, as with the variable used to analyze the oxidative system) were chosen to assess the influence of $\mathrm{NaHCO}_{3}$ on AnMS.

\section{Overall meta-analysis of AnMS}

The forest plots depicting the individual SMDs and associated 95\% CI and random-effect models for $\mathrm{pH}$, $\mathrm{HCO}_{3}{ }^{-}, \mathrm{BE}$ and $\mathrm{BLa}$ are presented in Figs. 2, 3, 4, 5 respectively.

The SMD for blood pH value was 1.38 (95\% CI: 0.97 to 1.79), indicating a significant effect during exercise between $\mathrm{NaHCO}_{3}$ and placebo conditions $(p<0.001)$ (Fig. 2). In addition, there was a significant effect during exercise after ingesting $\mathrm{NaHCO}_{3}$ on $\mathrm{HCO}_{3}{ }^{-}$(SMD = 1.63, $95 \%$ CI: 1.10 to $2.17, P<0.001$; Fig. 3$), \mathrm{BE}$ (SMD = 1.67, 95\% CI: 1.16 to 2.19, $\mathrm{P}<0.001$; Fig. 4) and BLa $(\mathrm{SMD}=0.72,95 \% \mathrm{CI}: 0.34$ to $1.11, \mathrm{P}<0.001$; Fig. 5$)$ in the blood. Moderate heterogeneity was detected among studies assessing $\mathrm{pH}\left(\mathrm{I}^{2}=69 \%\right)$ and $\mathrm{BLa}\left(\mathrm{I}^{2}=68 \%\right)$, whereas $\mathrm{HCO} 3$ - and $\mathrm{BE}$ presented a high heterogeneity $\left(\mathrm{I}^{2}=80 \%\right.$ and $\mathrm{I}^{2}=77 \%$ respectively).

\section{Sub-group analysis of AnMS}

A sub-group analysis was performed to evaluate the effect of $\mathrm{NaHCO}_{3}$ ingestion on exercise with different metabolic characteristics. There was a significant difference between two cohorts for $\mathrm{pH}$ value in anaerobicbased $\left(\mathrm{SMD}=1.38,95 \% \mathrm{CI}: 0.88\right.$ to $1.87, P<0.001, \mathrm{I}^{2}=$ $70 \%)$ and aerobic-based $(\mathrm{SMD}=1.39,95 \% \mathrm{CI}: 0.56$ to 2.22, $P=0.001, \mathrm{I}^{2}=72 \%$ ) exercise (Fig. 2). Similar to $\mathrm{HCO}_{3}{ }^{-}$and $\mathrm{BE}$, there was a significant difference between two cohorts for $\mathrm{HCO}_{3}{ }^{-}$and $\mathrm{BE}$ in anaerobicbased exercise $(\mathrm{SMD}=1.29,95 \% \mathrm{CI}$ : 0.77 to $1.18, P<$ $0.001, \mathrm{I}^{2}=73 \%$ and $\mathrm{SMD}=1.37,95 \% \mathrm{CI}: 0.94$ to 1.84 , $P<0.001, \mathrm{I}^{2}=67 \%$ respectively) and aerobic-based exercise $\left(\mathrm{SMD}=2.35,95 \% \mathrm{CI}: 1.06\right.$ to $3.64, P<0.001, \mathrm{I}^{2}=$ $83 \%$ and $\mathrm{SMD}=2.52,95 \% \mathrm{CI}: 1.07$ to $3.96, P<0.001$, $\mathrm{I}^{2}=84 \%$ respectively) (Figs. 3 and 4 ). 


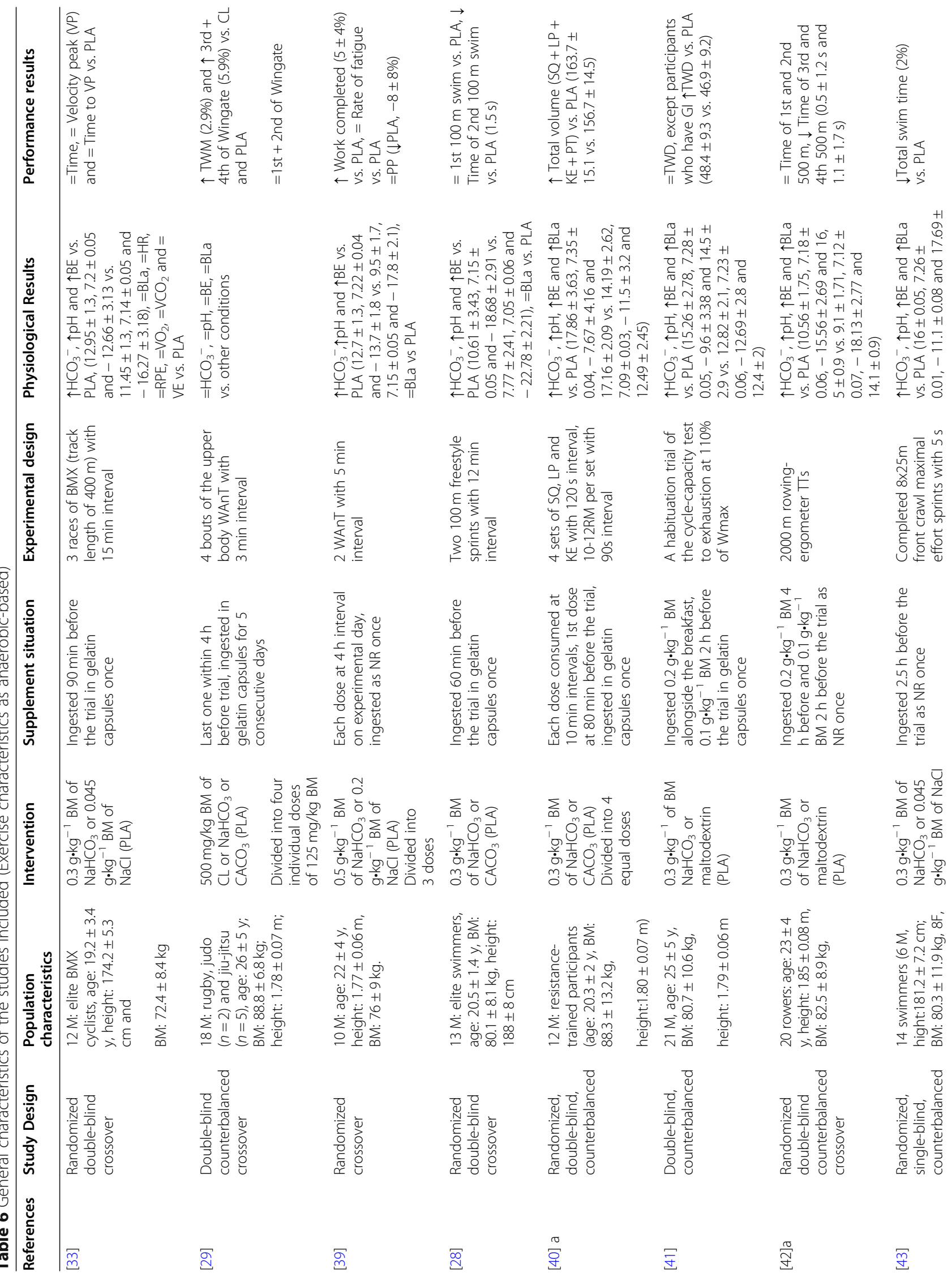




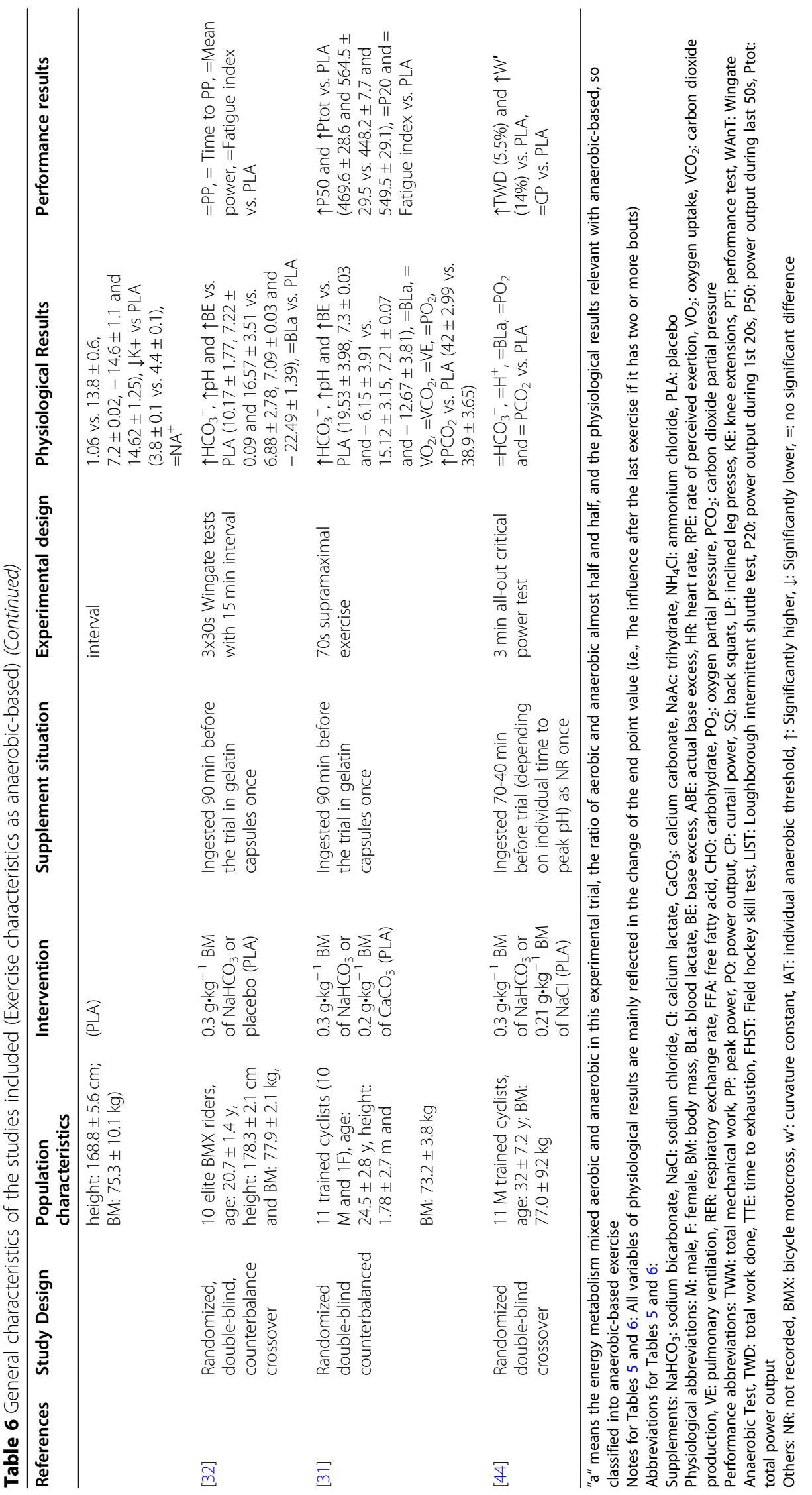




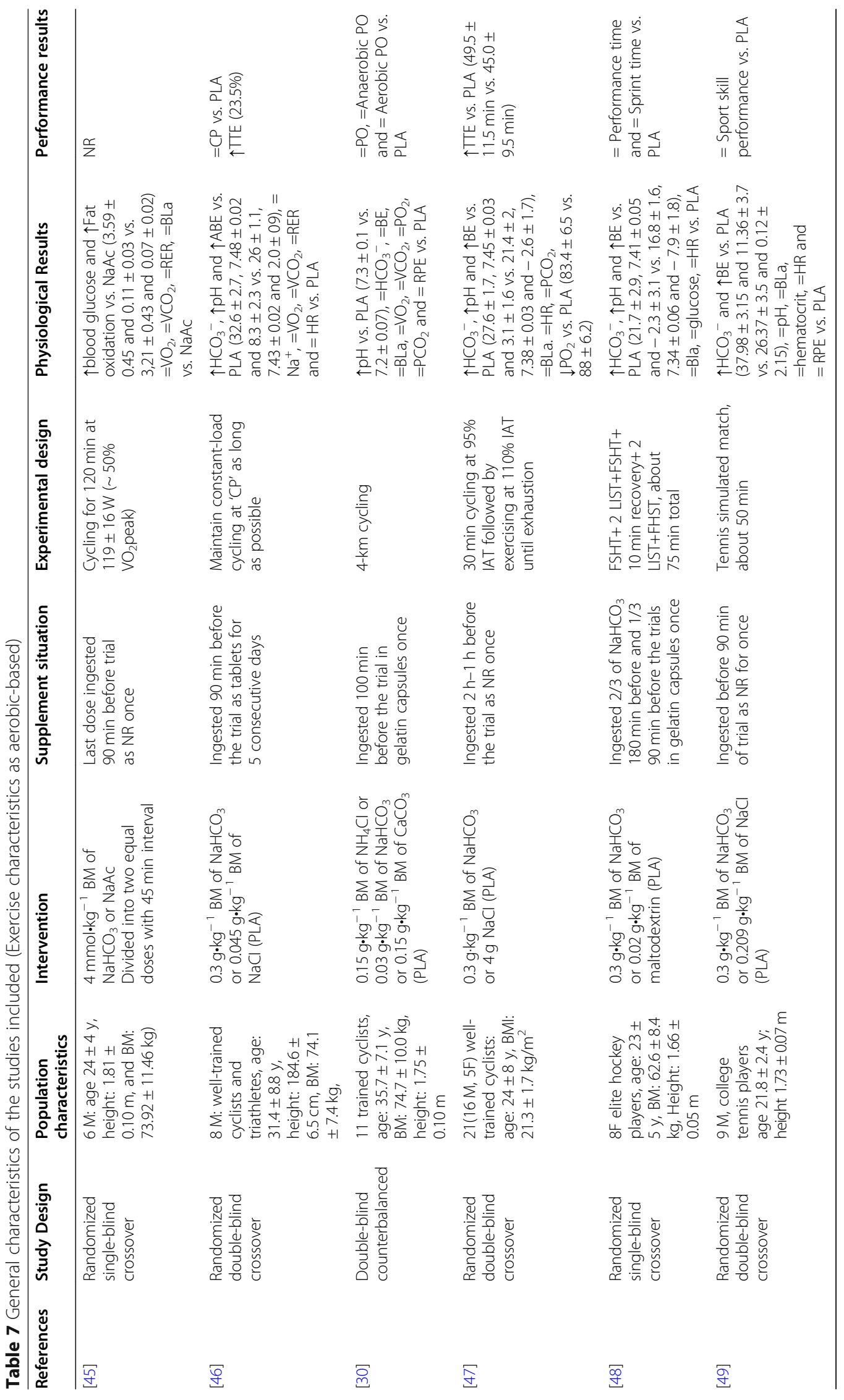




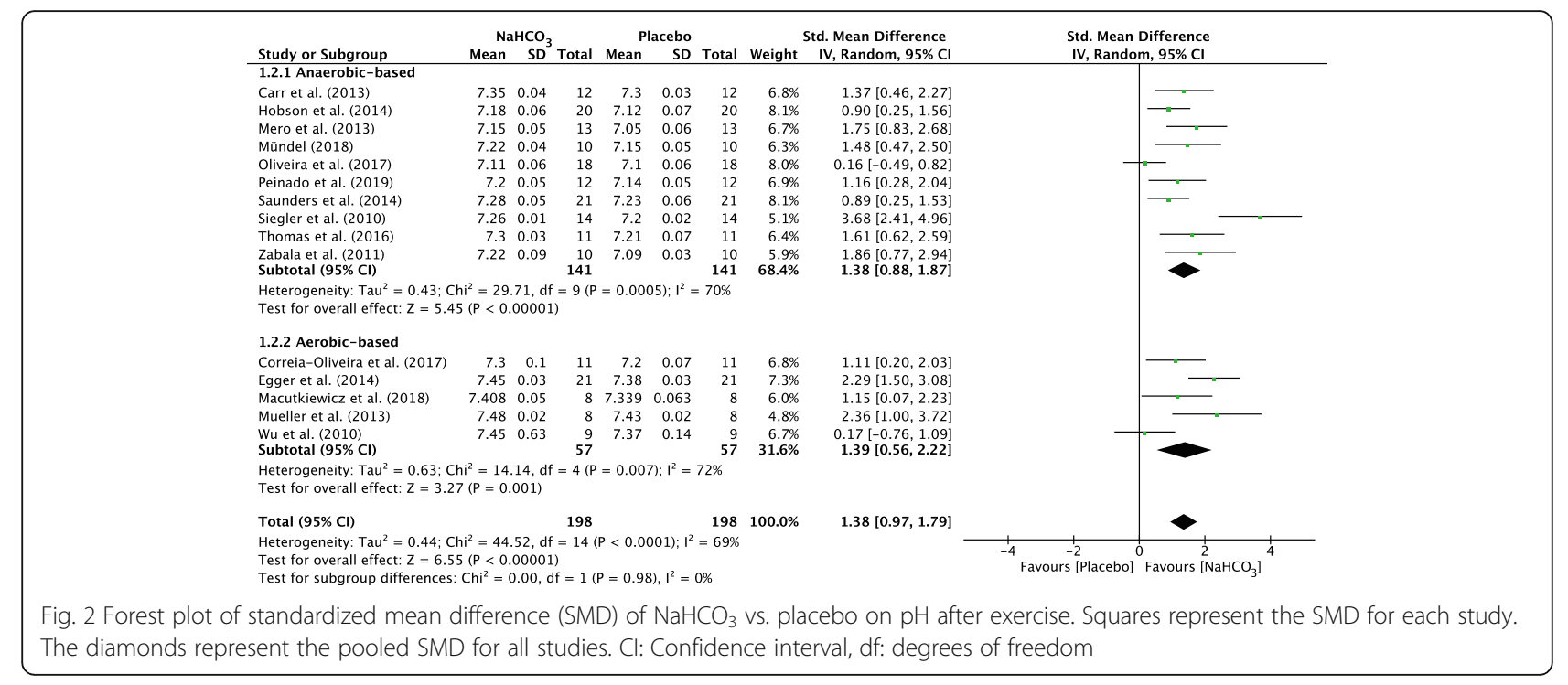

A significant difference between two cohorts was also found for BLa in anaerobic-based exercise $(\mathrm{SMD}=0.90$, 95\% CI: 0.40 to $1.41, P<0.001, \mathrm{I}^{2}=74 \%$ ) but a nonsignificant difference on aerobic-based exercise $(\mathrm{SMD}=$ $0.30,95 \% \mathrm{CI}:-0.1$ to $0.7, P=0.14)$. Heterogeneity was not detected among studies assessing $\mathrm{BLa}\left(\mathrm{I}^{2}=0 \%\right)$ in aerobic-based exercise. (Fig. 5).

\section{Strategic analysis of $\mathrm{NaHCO}_{3}$ in AnMS}

For anaerobic-based exercise (Table 6), 9 (82\%) out of 11 studies used $0.3 \mathrm{~g} \cdot \mathrm{kg}^{-1} \mathrm{BM}$ of $\mathrm{NaHCO}_{3}$ and the remaining 2 articles used $0.5 \mathrm{~g} \cdot \mathrm{kg}^{-1} \mathrm{BM}$. The duration was once in 10 (91\%) studies, while 1 study had duration of 5 consecutive days. The administration of $\mathrm{NaHCO}_{3}$ was in gelatin capsules in $7(64 \%)$ studies and not recorded in 4 studies (Fig. 6). More than half of the studies showed $\mathrm{NaHCO}_{3}$ ingestion 90-60 min before the trial, other studies shown it more than $2 \mathrm{~h}$ before the trial.

\section{The influence after ingesting $\mathrm{NaHCO}_{3}$ on the oxidative system} When performing long-term moderate-intensity exercise, the ventilation volume matches the energy metabolism rate, and it is necessary to constantly change the ratio between the body's oxygen uptake $\left(\mathrm{VO}_{2}\right)$ and carbon dioxide production $\left(\mathrm{VCO}_{2}\right)$. It is widely acknowledged that a higher $\mathrm{VO}_{2}$ is associated with a stronger aerobic capacity. Most of the $\mathrm{CO}_{2}$ (about $60-70 \%$ ) produced during muscle exercise is transported back to the heart in the form of $\mathrm{HCO}_{3}^{-}$[1]. $\mathrm{CO}_{2}$ and water molecules combine to form carbonic acid, which is unstable and will soon dissolve, forming free $\mathrm{H}^{+}$and $\mathrm{HCO}_{3}{ }^{-}$:

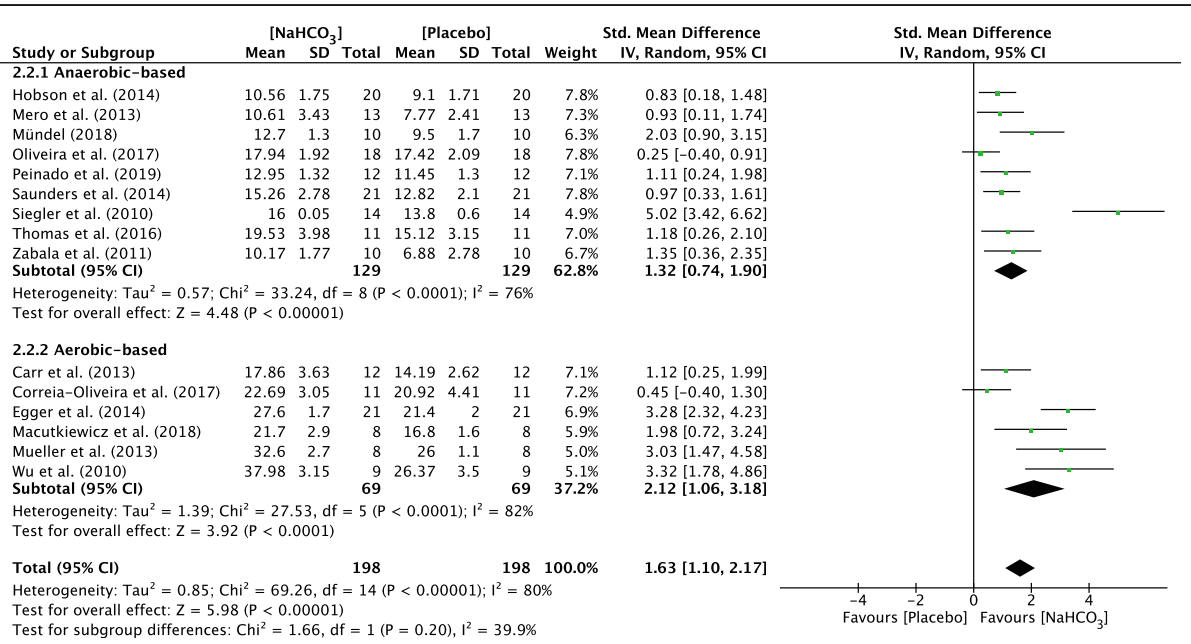

Fig. 3 Forest plot of standardized mean difference (SMD) of $\mathrm{NaHCO}_{3}$ vs. placebo on $\mathrm{HCO}_{3}$ - after exercise. Squares represent the SMD for each study. The diamonds represent the pooled SMD for all studies. Cl: Confidence interval, df: degrees of freedom. 


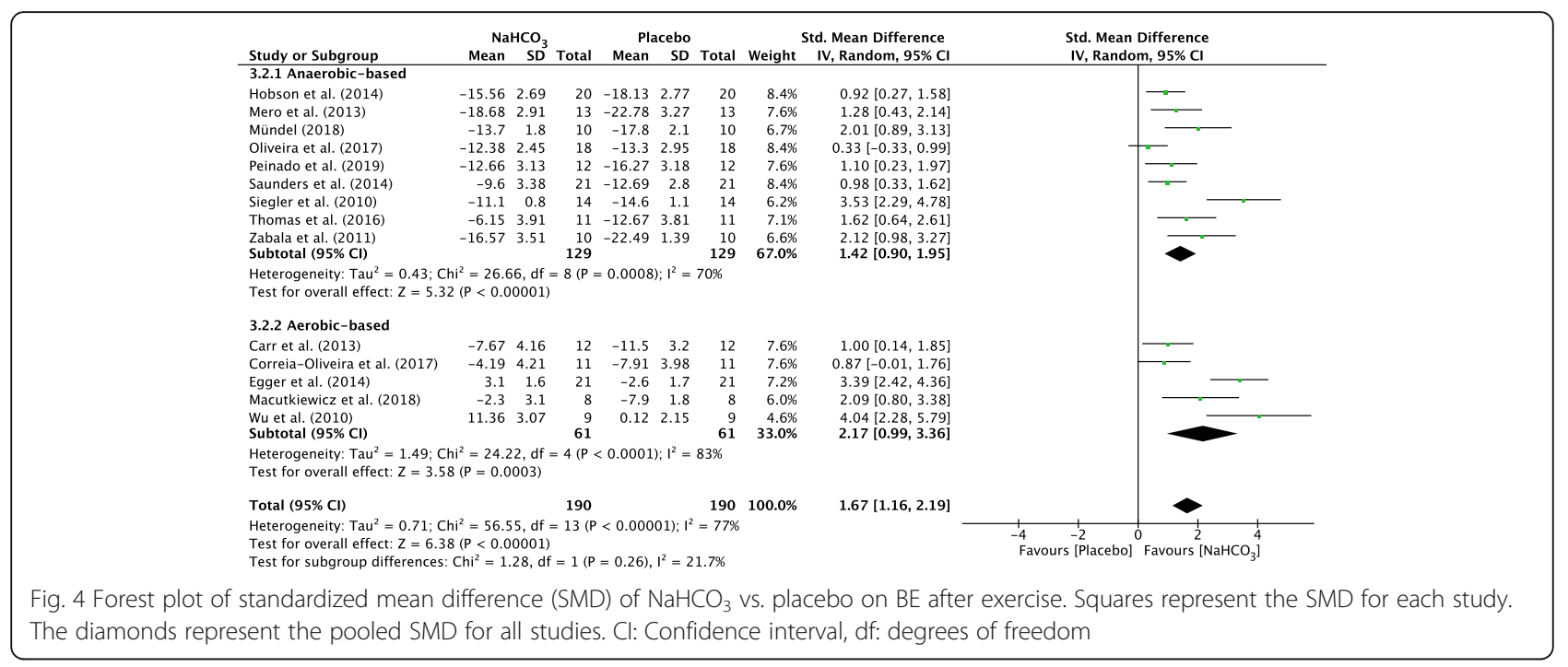

$$
\mathrm{CO}_{2}+\mathrm{H}_{2} \mathrm{O} \rightarrow \mathrm{H}_{2} \mathrm{CO}_{3} \rightarrow \mathrm{H}^{+}+\mathrm{HCO}_{3}{ }^{-},
$$

When the blood enters the area where the partial pressure of carbon dioxide $\left(\mathrm{PCO}_{2}\right)$ in the lungs is low, $\mathrm{H}^{+}$ will combine with $\mathrm{HCO}_{3}{ }^{-}$to form carbonic acid, and then decompose into $\mathrm{CO}_{2}$ and water:

$$
\mathrm{H}^{+}+\mathrm{HCO}_{3}{ }^{-} \rightarrow \mathrm{H}_{2} \mathrm{CO}_{3} \rightarrow \mathrm{CO}_{2}+\mathrm{H}_{2} \mathrm{O}
$$

After $\mathrm{CO}_{2}$ enters the lungs, it is eliminated by dissociation, which is the main way to reduce $\mathrm{H}^{+}$concentration when $\mathrm{CO}_{2}$ is eliminated [1].

The amount and rate of gas exchange across the respiratory membrane are mainly determined by the partial pressure of each gas. The gas diffuses along the pressure gradient, from the part with the higher pressure to the lower pressure part. At standard atmospheric pressure, the partial pressure of oxygen $\left(\mathrm{PO}_{2}\right)$ outside the body is greater than that inside the body after alveolar gas exchange. When the exercising muscles require more oxygen to meet metabolic needs, the venous oxygen is depleted and accelerates the alveolar gas exchange, resulting in $\mathrm{PO}_{2}$ reduction [1]. Therefore, $\mathrm{O}_{2}$ enters the blood and $\mathrm{CO}_{2}$ leaves the blood. $\mathrm{PCO}_{2}$ is mainly used to determine whether there is respiratory acidosis or alkalosis. Increased $\mathrm{PCO}_{2}$ suggests that there is insufficient lung ventilation, and $\mathrm{CO}_{2}$ retention in the body, which leads to respiratory acidosis. Lower $\mathrm{PCO}_{2}$, indicating hyperventilation (such as deeper or faster breathing), and excessive $\mathrm{CO}_{2}$ elimination in the body, leads to respiratory alkalosis [1]. Therefore, an increase in $\mathrm{PCO}_{2}$ will cause an increase in $\mathrm{CO}_{2}$ in the blood, which will result in a decrease in the $\mathrm{pH}$ value.

To sum up, the change of $\mathrm{O}_{2}$ and $\mathrm{CO}_{2}$ during longterm moderate-intensity exercise can reflect aerobic

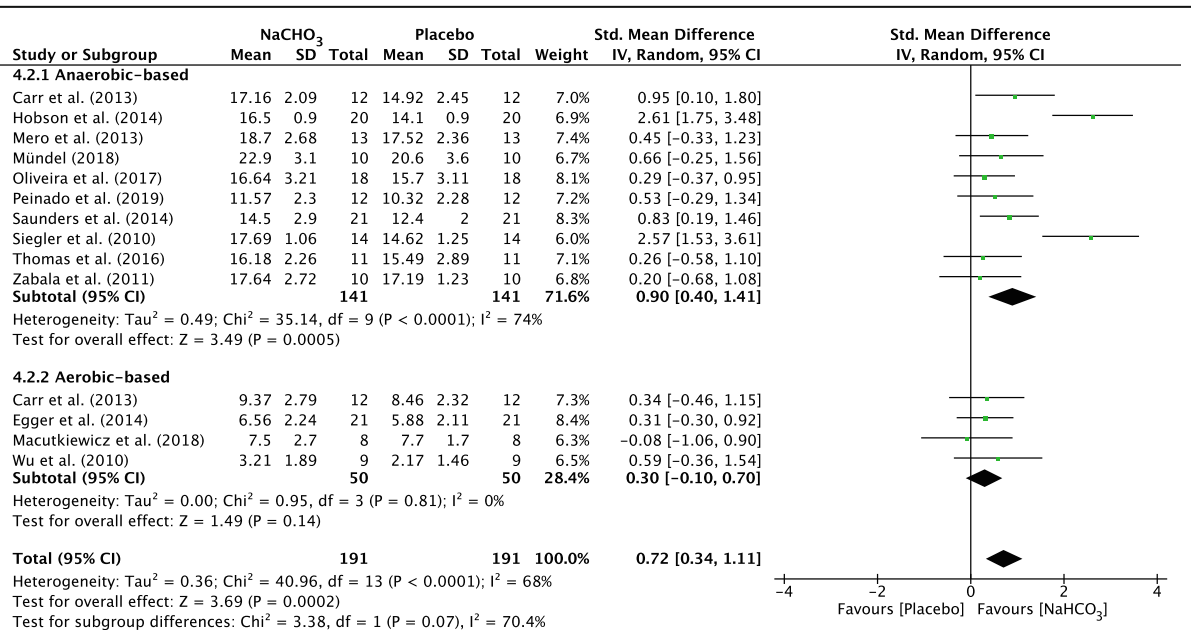

Fig. 5 Forest plot of standardized mean difference (SMD) of $\mathrm{NaHCO}_{3}$ Vs. placebo on BLa after exercise. Squares represent the SMD for each study. The diamonds represent the pooled SMD for all studies. Cl: Confidence interval, df: degrees of freedom 


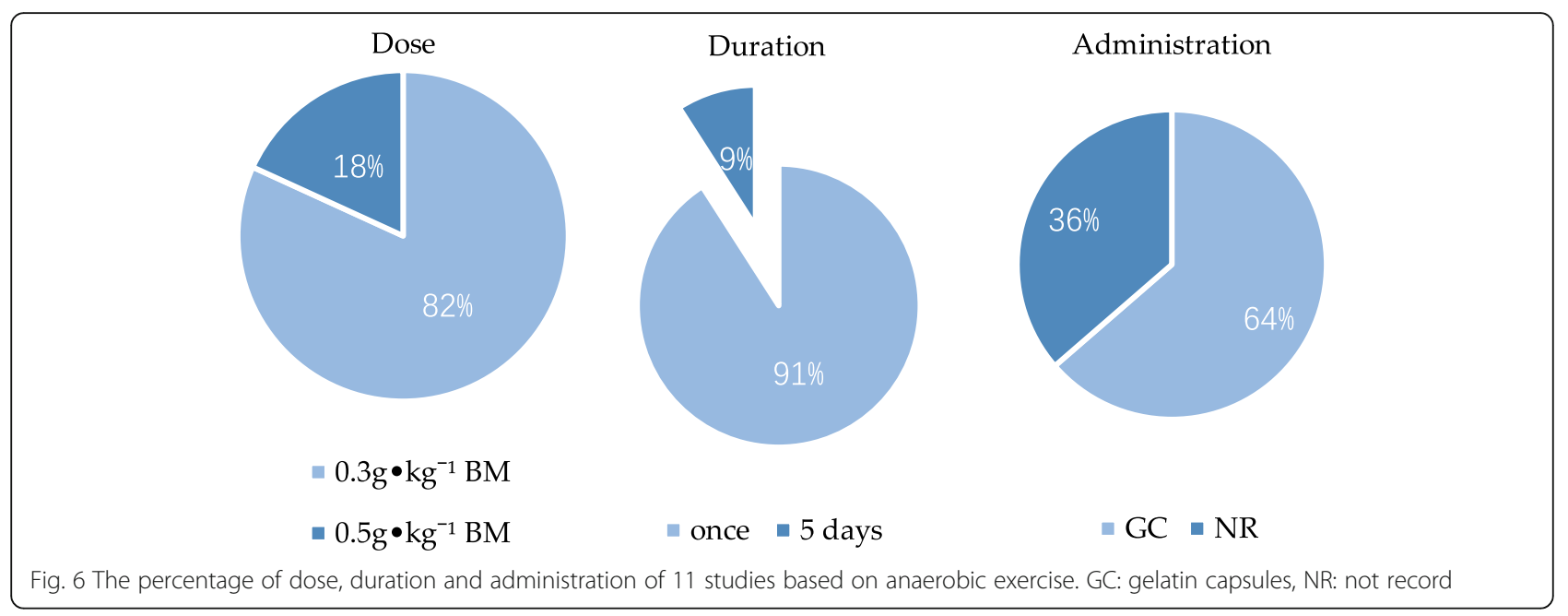

capacity to a certain extent. For that reason, the four variables (i.e., $\mathrm{VO}_{2}, \mathrm{VCO}_{2}, \mathrm{PO}_{2}$ and $\mathrm{PCO}_{2}$ ) were chosen to assess the influence of $\mathrm{NaHCO}_{3}$ on the oxidative system.

\section{Overall meta-analysis of the oxidative system}

The forest plots depicting the individual SMDs and associated 95\% $\mathrm{CI}$ and random-effect models for $\mathrm{VO}_{2}$, $\mathrm{VCO}_{2}, \mathrm{PO}_{2}$ and $\mathrm{PCO}_{2}$ are presented in Fig. 7.

The SMD for $\mathrm{VO}_{2}$ was 0.06 (95\% CI: - 0.34 to 0.46), indicating a non-significant effect during exercise between $\mathrm{NaHCO}_{3}$ and placebo cohorts $(p=0.78)$ (Fig. 7a). Similarly, there was a non-significant effect during exercise after ingestion of $\mathrm{NaHCO}_{3}$ on $\mathrm{VCO}_{2}(\mathrm{SMD}=0.21$, 95\% CI: -0.19 to $0.62, P=0.30)$ and $\mathrm{PO}_{2}(\mathrm{SMD}=-0.19$, 95\% CI: -0.66 to $0.29, P=0.44$ ) (Fig. $7 \mathrm{~b}$ and c), but a significant effect on $\mathrm{PCO}_{2}(\mathrm{SMD}=0.51,95 \% \mathrm{CI}$ : 0.13 to $0.90, P=0.009$ ) (Fig. $7 \mathrm{~d}$ ). Heterogeneity was not detected among studies assessing $\mathrm{VO}_{2}, \mathrm{VCO}_{2}$ and $\mathrm{PCO}_{2}\left(\mathrm{I}^{2}=0 \%\right)$ and $\mathrm{PO}_{2}$ presented a low heterogeneity $\left(\mathrm{I}^{2}=32 \%\right)$, shown in Fig. 7a, b, c and d respectively.

\section{Sub-group analysis of the oxidative system}

A sub-group analysis was performed to evaluate the effect of $\mathrm{NaHCO}_{3}$ ingestion on exercise with different metabolic characteristics. There was a non-significant difference between two cohorts for $\mathrm{VO}_{2}$ in anaerobicbased (SMD $=0.20,95 \% \mathrm{CI}:-0.38$ to $0.77, P=0.50, \mathrm{I}^{2}=$ $0 \%$ ) and aerobic-based (SMD $=-0.08,95 \% \mathrm{CI}:-0.63$ to $0.48, P=0.79, I^{2}=0 \%$ ) exercise (Fig. 7a). Similar to $\mathrm{VCO}_{2}$ and $\mathrm{PO}_{2}$, there was a non-significant difference between cohorts for $\mathrm{VCO}_{2}$ and $\mathrm{PO}_{2}$ in anaerobic-based exercise $(\mathrm{SMD}=0.35,95 \% \mathrm{CI}:-0.24$ to $0.93, P=0.25$, $\mathrm{I}^{2}=0 \%$ and $\mathrm{SMD}=0.07,95 \% \mathrm{CI}:-0.53$ to $0.66, P=0.83$, $\mathrm{I}^{2}=0 \%$ respectively) and aerobic-based exercise (SMD = $0.09,95 \%$ CI: -0.46 to $0.65, P=0.74, \mathrm{I}^{2}=0 \%$ and $\mathrm{SMD}=$
$-0.37,95 \% \mathrm{CI}:-1.13$ to $0.40, P=0.35, \mathrm{I}^{2}=54 \%$ respectively) (b and $\mathrm{c}$ in Fig. 7).

The opposite results are shown in Fig. $7 \mathrm{~d}$. There was a significant difference between cohorts for $\mathrm{PCO}_{2}$ in anaerobic-based (SMD $=0.87,95 \% \mathrm{CI}: 0.25$ to $1.50, P=$ 0.006 ) but not aerobic-based ( $\mathrm{SMD}=0.29,95 \% \mathrm{CI}$ : 0.20 to $0.78, \mathrm{P}=0.25$ ) exercise. Heterogeneity was not detected among studies assessing $\mathrm{PCO}_{2}$ in anaerobicbased $\left(\mathrm{I}^{2}=0 \%\right)$ and aerobic-based $\left(\mathrm{I}^{2}=0 \%\right)$ exercise.

\section{Strategic analysis of $\mathrm{NaHCO}_{3}$ on the oxidative system}

For aerobic-based exercise (Table 7), 5 (83\%) out of 6 studies used $0.3 \mathrm{~g} \cdot \mathrm{kg}^{-1} \mathrm{BM}$ of $\mathrm{NaHCO} 3$ and 1 article used $4 \mathrm{mmol} \cdot \mathrm{kg}^{-1}$ (about $0.336 \mathrm{~g} \cdot \mathrm{kg}^{-1}$ ). The duration was once in $5(83 \%)$ out of 6 studies, while 1 study had a duration of 5 consecutive days. The administration of $\mathrm{NaHCO}_{3}$ was in tablets in 1 study, gelatin capsules in 2 studies and not recorded in 3 studies (Fig. 8). Half of the studies showed $\mathrm{NaHCO} 3$ ingestion $90 \mathrm{~min}$ before the trial, other studies showed it $3-1.5 \mathrm{~h}$ before the trial.

\section{Discussion}

To our knowledge, the present study is the first to assess the contribution of $\mathrm{NaHCO}_{3}$ ingestion on energy metabolism during exercise with a meta-analytic statistical technique using Review Manager 5.3 (v5.3, Cochrane Collaboration, Copenhagen, Denmark, 2020). The main findings of this analysis indicated that ingestion of $\mathrm{NaHCO}_{3}$ improves $\mathrm{pH}, \mathrm{HCO}_{3}{ }^{-}$and $\mathrm{BE}$ in the blood during exercise compared to a placebo (Figs. 2, 3, 4). However, BLa can be improved in anaerobic-based but not in aerobic-based exercise through ingestion of $\mathrm{NaHCO}_{3}$ (Fig. 5). Furthermore, compared to a placebo, ingestion of $\mathrm{NaHCO}_{3}$ during exercise does not improve $\mathrm{VO}_{2}, \mathrm{VCO}_{2}$ and $\mathrm{PO}_{2}$, although it improves $\mathrm{PCO}_{2}$ in anaerobic-based but not aerobic-based exercise (Fig. 7). Collectively these results indicate that ingestion of 


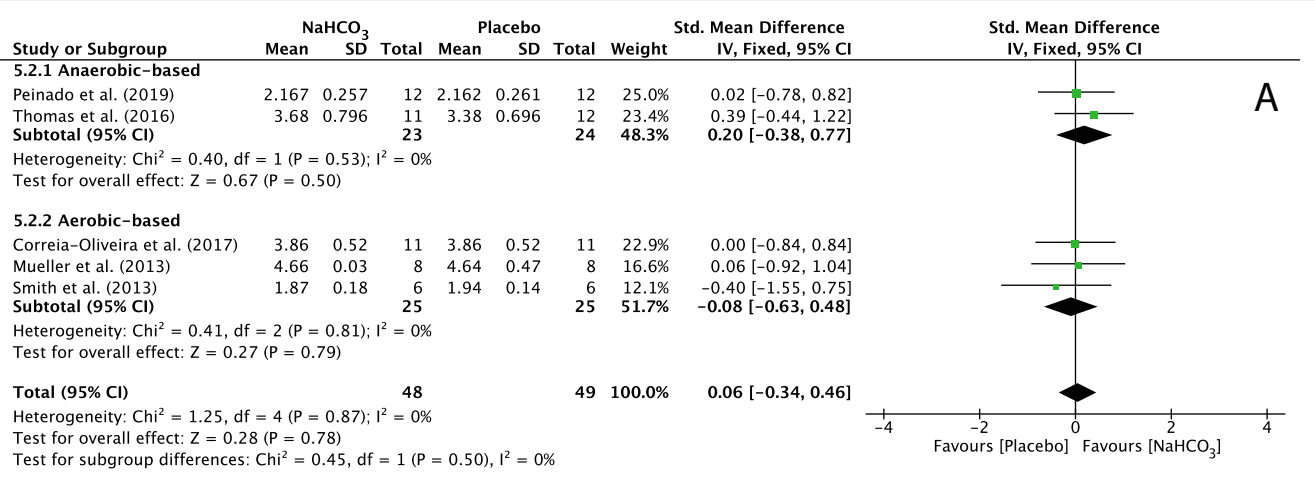

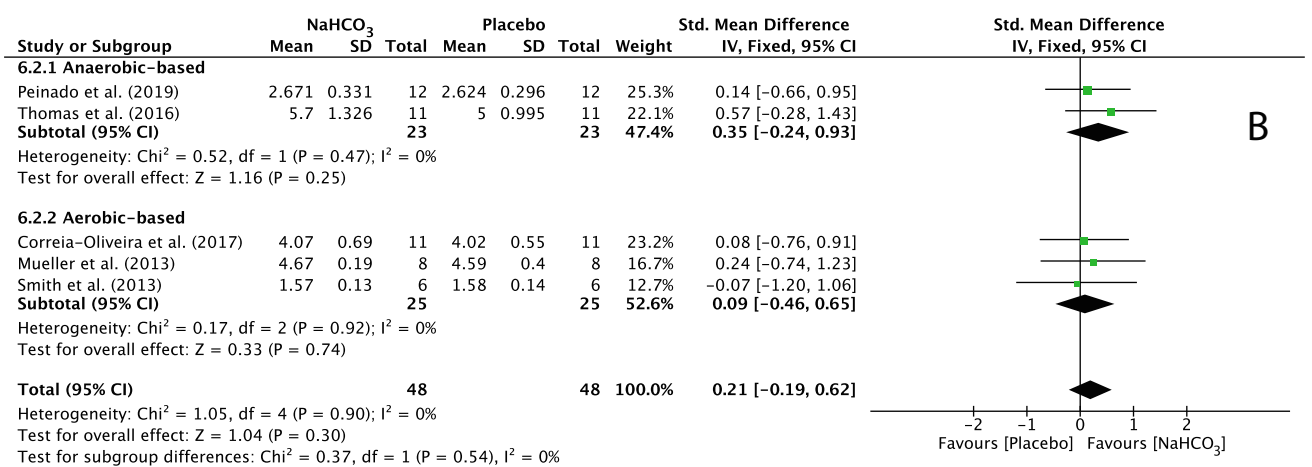

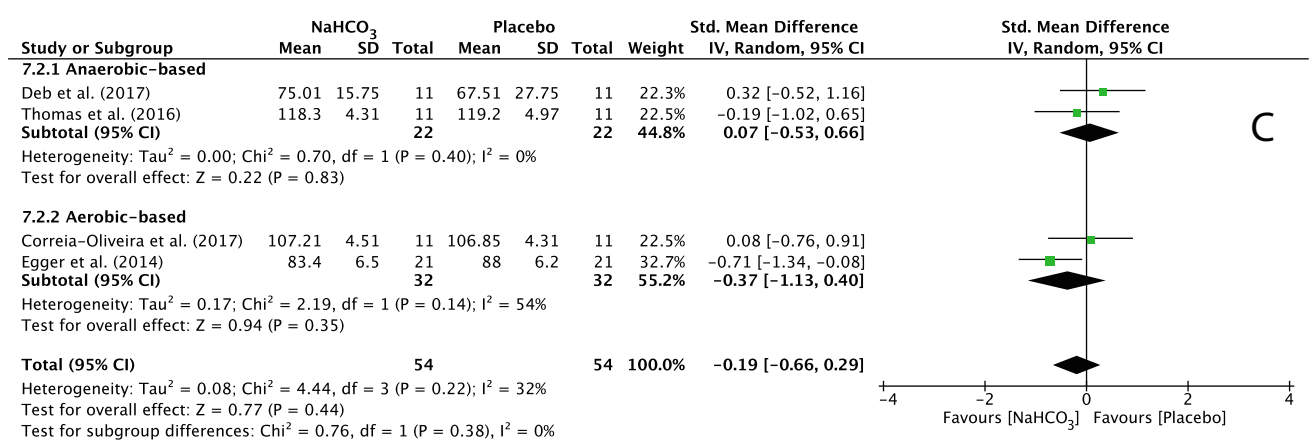

(ifferences: $\mathrm{Chi}^{2}=0.76, \mathrm{df}=1(\mathrm{P}=0.38), \mathrm{I}^{2}=0 \%$

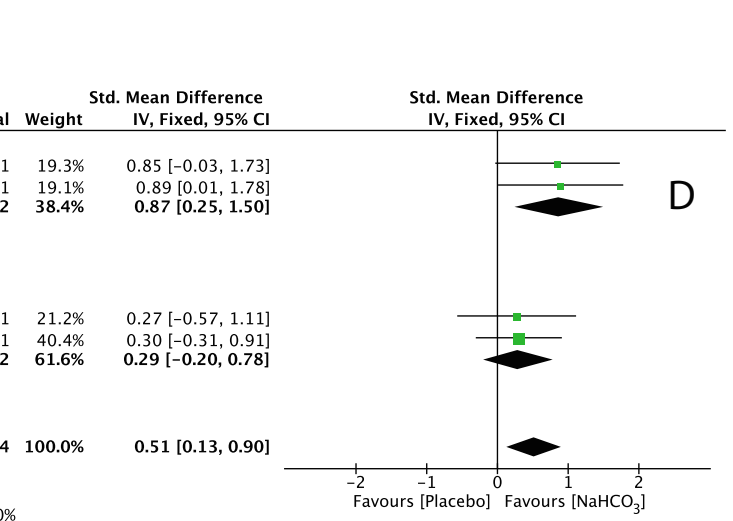

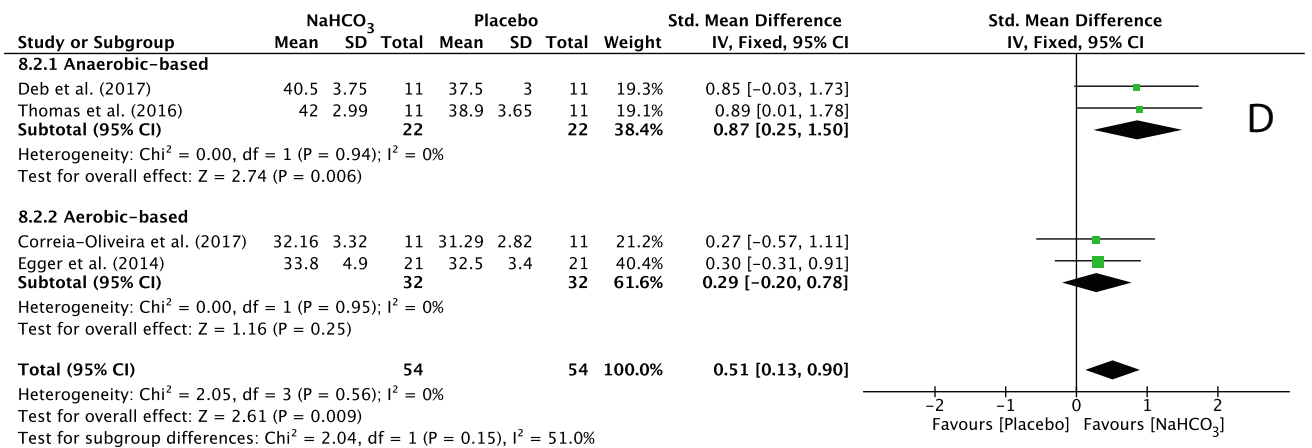

Fig. 7 Forest plot of standardized mean difference (SMD) of $\mathrm{NaHCO}_{3}$ vs. placebo on $\mathrm{VO}_{2}(A), \mathrm{VCO}_{2}(\mathrm{~B}), \mathrm{PO}_{2}(\mathrm{C})$ and $P C \mathrm{P}_{2}(\mathrm{D})$ after exercise. Squares represent the SMD for each study. The diamonds represent the pooled SMD for all studies. Cl: Confidence interval, df: degrees of freedom 


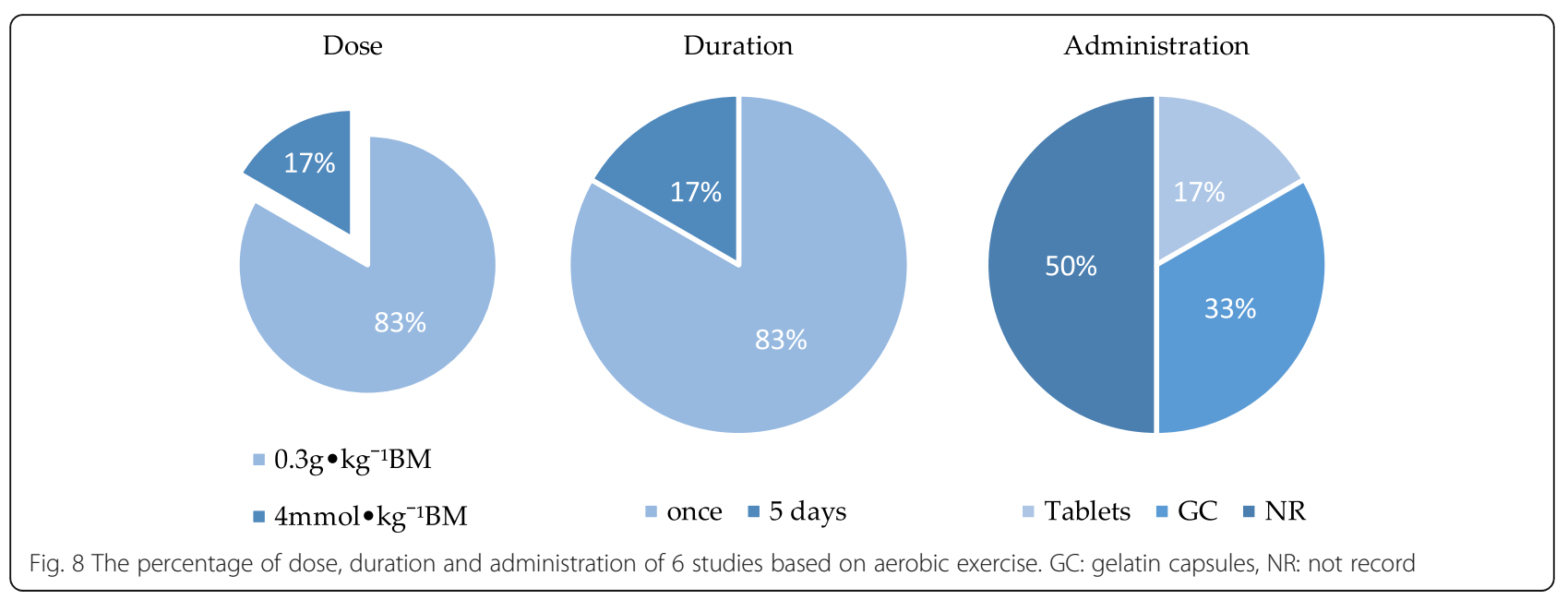

$\mathrm{NaHCO}_{3}$ is better than a placebo to improve AnMS but makes no difference to the oxidative system.

The discrepancies in the studies reported in this metaanalysis need to be considered. The extracellular to intracellular $\mathrm{pH}$ gradient increases as $\mathrm{HCO}_{3}{ }^{-}$is impermeable to cellular membranes [50], resulting in a greater efflux of $\mathrm{H}^{+}$and lactate from active muscles [51]. This occurs via either simple diffusion or by the lactate or $\mathrm{H}^{+}$ co-transporters [5]. It has been suggested that lactate efflux from muscles is higher as a result of extracellular alkalosis. However, Fig. 5 shows that there was no significant difference for BLa in an aerobic-based situation. That may explain the lack of effect with ingestion of $\mathrm{NaHCO}_{3}$ on performance that is based on the oxidative system, despite the significant effects on AnMS.

Therefore, a sensitivity analysis was performed to verify the results. According to the evaluation results in Table 5, the study with the lowest score [43] and another 5 articles [33, 41, 42, 44, 45] that were not given full marks were excluded. These sensitivity analysis results were similar to those of the original meta-analysis.

\section{Discussion on AnMS}

Results in the present analysis indicate that $\mathrm{NaHCO}_{3}$ ingestion is effective in improving AnMS, which may be able to improve sport performance based on anaerobic capacity. The performance results of included studies showed that performance improved or was maintained the same when ingesting $\mathrm{NaHCO}_{3}$, while a placebo showed a decline in sport performance. (Table 6). This result is different from that of other meta-analyses [52, 53], but similar to several individual studies which did not meet the present eligibility criteria $[54,55]$. Two included studies [32, 33] reported no improvement in sport performance, and we found that the experimental exercise in these two articles were more likely based on the ATP-CP system to obtain energy (Table 6). This is similar to previous studies $[12,56]$, where the ATP-CP system was not affected by $\mathrm{NaHCO}_{3}$ ingestion.

The key point of the contraindications in different results may be the gastrointestinal (GI) problems caused by ingestion of $\mathrm{NaHCO}_{3}$. Because the bicarbonate buffer system is not solely responsible for blood $\mathrm{pH}$ and is also vital in other systems, such as the stomach and duodenum by neutralizing gastric acid, abdominal pain and diarrhea are often experienced by individuals who take $\mathrm{NaHCO}_{3}[36,57]$. An article included in the present study also illustrated this problem [41]. While the results among all subjects indicated that the intake of $\mathrm{NaHCO}_{3}$ has no effect on sports performance, after excluding subjects who had GI problems with ingestion of $\mathrm{NaHCO}_{3}$, a significant difference in sports performance was observed. However, in this meta-analysis, the author extracted the data of all subjects from this article and verified that it did not affect the results of the metaanalysis. In response to the GI problems, some countermeasures have been taken that have been scientifically proven to alleviate or prevent GI problems. For example, ingestion of a large amount of water [58], with food [9], with carbohydrate [59] or administration as entericformulated capsules [60]. More measures to prevent GI problems may help demonstrate the improvement in sport performance with the intake of $\mathrm{NaHCO}_{3}$ as subjects are not troubled by GI problems.

\section{Discussion on the oxidative system}

Although the overall $\mathrm{PCO}_{2}$ in Fig. 7 shows a significant difference, aerobic-based exercise alone presented no significant difference. Therefore, ingestion of $\mathrm{NaHCO}_{3}$ does not benefit exercise based on the oxidative system, which means it may not be able to improve sport performance that is based on aerobic capacity. This is similar to the performance results shown in Table 7 , with the exception of one study [45] that did not record performance results and two other studies that had 
results possibly due to chronic ingestion [46], or the decrease in $\mathrm{PO}_{2}$ [47] due to ingestion of $\mathrm{NaHCO}_{3}$. As mentioned before, $\mathrm{PO}_{2}$ reduction accelerates alveolar gas exchange. The results based on this meta-analysis, that the sport performance based on aerobic capacity is not affected by $\mathrm{NaHCO}_{3}$ ingestion, is different from some previous studies [14, 61], but similar to other studies [15, 62].

There is a reason why $\mathrm{NaHCO}_{3}$ intake will cause different results for aerobic-based exercise. Whether ATP is produced under aerobic or anaerobic conditions, glycogen plays an important role. Glycogen can provide energy to maintain moderate-intensity exercise for 3 to 5 min under aerobic conditions. The reason some studies $[14,61]$ have different results from the present study may be because they are based on the aerobic energy supply form of muscle glycogen. However, the studies included in this present meta-analysis are based on the aerobic energy supply form of fat (according to the exercise time, energy from fat can be maintained for $1-2 \mathrm{~h}$ or more) (Table 1). Different forms of the oxidative system supply may be one of the reasons for the different performance results after ingestion of $\mathrm{NaHCO}_{3}$.

\section{Limitations}

A number of limitations may be present in this metaanalysis and should be considered. Firstly, the choice of variables that reflect the ATP-CP, glycolytic and oxidative systems may not be a good representative of performance. As we know, the substrates of ATP recovery for the ATP-CP, glycolytic and oxidative system are ATP/PCr, glucose and fat (i.e. free fatty acid [FFA], which are the main energy sources for the oxidative system) [1] respectively. The ideal way is to use these variables because the changes in their content can directly reflect the changes in the capacity of each energy metabolism system. However, a total of 9 articles from the initial search analyzed using these parameters (i.e., ATP, PCr, glucose or FFA), and there was only one left after excluding articles that did not meet the eligibility criteria. This is why we chose $\mathrm{pH}, \mathrm{HCO}_{3}{ }^{-}, \mathrm{BE}$ and BLa; $\mathrm{VO}_{2}, \mathrm{VCO}_{2}, \mathrm{PO}_{2}$ and $\mathrm{PCO}_{2}$ that reflect the changes in the capacity of each energy metabolism system indirectly instead, which may affect the accuracy of the research results.

Additionally, this study analyzes the integration of the ATP-CP and glycolytic system as an AnMS, but in fact the research results of this article may be biased towards the glycolytic system. ATP resynthesis into ATP-CP occurs very quickly, and intake of $\mathrm{NaHCO}_{3}$ may be too late to have an effect. Therefore, there is a lack of a specific influence of ingestion of $\mathrm{NaHCO}_{3}$ on the ATP-CP system, while other studies have reported that induced alkalosis does not affect the ATP-CP system, but does benefit the glycolytic system and does not impact the oxidative system [11, 17], similar to the results in the present meta-analysis.

\section{Conclusions}

This meta-analysis provides evidence that ingestion of $\mathrm{NaHCO}_{3}$ increases the content of $\mathrm{pH}, \mathrm{HCO}_{3}{ }^{-}, \mathrm{BE}$ and lactate in the blood, that may be beneficial to exercise based on the anaerobic metabolism system, especially based on the glycolytic system. The ideal way is to ingest it in a gelatin capsule in an acute mode and use a dose of $0.3 \mathrm{~g} \cdot \mathrm{kg}^{-1} \mathrm{BM}$ of $\mathrm{NaHCO}_{3} 90 \mathrm{~min}$ before the trial. Furthermore, the specific form of aerobic oxidative supply should be considered before ingesting $\mathrm{NaHCO}_{3}$ when doing aerobic exercise. Therefore, athletes and coaches should take notice that anaerobic and aerobic exercise and sports capacity based on the glycolytic system may be improved by supplementing with $\mathrm{NaHCO}_{3}$.

\section{Abbreviations}

$\mathrm{NaHCO}_{3}$ : Sodium bicarbonate; $\mathrm{HCO}_{3}^{-}$: Bicarbonate ion; $\mathrm{BE}$ : Base excess; BLa: Blood lactate; $\mathrm{VO}_{2}$ : Oxygen uptake; $\mathrm{VCO}_{2}$ : Carbon dioxide production;

$\mathrm{PO}_{2}$ : Partial pressure of oxygen; $\mathrm{PCO}_{2}$ : Partial pressure of carbon dioxide; AnMS: Anaerobic metabolism system; ATP: Adenosine triphosphate;

CP: Creatine phosphate; PCr: Phosphocreatine; ADP: Adenosine diphosphate; CUE: Continuous unit of energy; SMD: Standardized mean differences; SE: Standard error; SD: Standard deviation; Cl: Confidence interval;

Gl: Gastrointestinal; FFA: Free fatty acid

\section{Acknowledgments}

The authors are particularly grateful to Universidad Politécnica de Madrid and Universidad Europea.

\section{Authors' contributions}

J.L.C.: conceptualization, conceived and designed the investigation, interpreted the data, drafted the paper, and approved the final version. H.X.: investigation, meta-analysis and interpreted the data, wrote the manuscript and submitted the paper. D.M.L: methodology, analyzed and interpreted the data. (H.P.G):: critically reviewed the paper, approved the final version submitted for publication, and funding acquisition. S.L.J.: critically reviewed the paper, interpreted the data and funding acquisition. All authors have read and agreed to the published version of the manuscript.

Funding

This study has no external funding.

\section{Availability of data and materials}

The data used and/ or analyzed during the current study are available from the corresponding author on reasonable request.

\section{Ethics approval and consent to participate Not applicable.}

\section{Consent for publication}

Not applicable.

\section{Competing interests}

The authors declare that they have no competing interests.

\section{Author details}

${ }^{1}$ Faculty of Physical Activity and Sport science, Universidad Politécnica de Madrid, Madrid, Spain. ${ }^{2}$ Faculty of Sport Sciences, Universidad Europea de Madrid, Madrid, Spain. ${ }^{3}$ Centre for Sport Studies, Rey Juan Carlos University, Fuenlabrada, Spain. 
Received: 26 August 2020 Accepted: 22 January 2021

\section{Published online: 05 February 2021}

\section{References}

1. Kenney WL, Wilmore $J H$, and Costill DL: Physiology of sport and exercise: Human kinetics; 2015(Series Editor).

2. MacLaren D and Morton J: Biochemistry for sport and exercise metabolism: John Wiley \& Sons; 2011(Series Editor).

3. Sahlin K. Muscle energetics during explosive activities and potential effects of nutrition and training. Sports Med. 2014:44:167-73.

4. Zinner C, Wahl P, Achtzehn S, et al. Effects of bicarbonate ingestion and high intensity exercise on lactate and $\mathrm{h}+-$-ion distribution in different blood compartments. Eur J Appl Physiol. 2011;111:1641-8.

5. Juel C. Current aspects of lactate exchange: lactate/h+ transport in human skeletal muscle. Eur J Appl Physiol. 2001;86:12-6.

6. Burke LM: Practical considerations for bicarbonate loading and sports performance. In Nutritional coaching strategy to modulate training efficiency. Volume 75. Edited by Tipton KD and VanLoon LJC; 2013:15-26.

7. Carr AJ, Hopkins WG, Gore CJ. Effects of acute alkalosis and acidosis on performance: a meta-analysis. Sports Med. 2011;41:801-14.

8. Cameron SL, McLay-Cooke RT, Brown RC, et al. Increased blood ph but not performance with sodium bicarbonate supplementation in elite rugby union players. Int J Sport Nutr Exerc Metab. 2010;20:307-21.

9. Carr AJ, Slater GJ, Gore CJ, et al. Effect of sodium bicarbonate on [hco3 -], ph, and gastrointestinal symptoms. International Journal of Sport Nutrition \& Exercise Metabolism. 2011;21:189-94.

10. Limmer M, Sonntag J, de Marées M, et al. Effects of an alkalizing or acidizing diet on high-intensity exercise performance under normoxic and hypoxic conditions in physically active adults: a randomized, crossover trial. Nutrients. 2020;12.

11. Lopes-Silva JP, Da Silva Santos JF, Artioli GG, et al. Sodium bicarbonate ingestion increases glycolytic contribution and improves performance during simulated taekwondo combat. Eur J Sport Sci. 2018;18:431-40.

12. Stephens TJ, McKenna MJ, Canny BJ, et al. Effect of sodium bicarbonate on muscle metabolism during intense endurance cycling. Med Sci Sports Exerc. 2002;34:614-21.

13. Edge J, Eynon N, McKenna MJ, et al. Altering the rest interval during highintensity interval training does not affect muscle or performance adaptations. Exp Physiol. 2013;98:481-90.

14. Maliqueo SAG, Ojeda ÁCH, Barrilao RG, et al. Time to fatigue on lactate threshold and supplementation with sodium bicarbonate in middledistance college athletes. Archivos de Medicina del Deporte. 2018;35:16-22.

15. Northgraves MJ, Peart DJ, Jordan CA, et al. Effect of lactate supplementation and sodium bicarbonate on 40-km cycling time trial performance. J Strength Cond Res. 2014;28:273-80.

16. Krustrup P, Ermidis G, Mohr M. Sodium bicarbonate intake improves highintensity intermittent exercise performance in trained young men. J Int Soc Sport Nutr. 2015;12.

17. da Silva RP, de Oliveira LF, Saunders B, et al. Effects of $\beta$-alanine and sodium bicarbonate supplementation on the estimated energy system contribution during high-intensity intermittent exercise. Amino Acids. 2019;51:83-96.

18. McGinley C, Bishop DJ. Influence of training intensity on adaptations in acid/base transport proteins, muscle buffer capacity, and repeated-sprint ability in active men. J Appl Physiol. 2016;121:1290-305.

19. Miller $P$, Robinson AL, Sparks SA, et al. The effects of novel ingestion of sodium bicarbonate on repeated sprint ability. J Strength Cond Res. 2016; 30:561-8.

20. Hadzic M, Eckstein ML, Schugardt M. The impact of sodium bicarbonate on performance in response to exercise duration in athletes: a systematic review. J Sports Sci Med. 2019;18:271-81.

21. Price $M$, Moss $P$, Rance $S$. Effects of sodium bicarbonate ingestion on prolonged intermittent exercise. Med Sci Sports Exerc. 2003;35:1303-8.

22. Simoneau JA, Bouchard C. Human variation in skeletal muscle fiber-type proportion and enzyme activities. Am J Phys. 1989;257:E567-72.

23. Heikkilä M, Valve R, Lehtovirta $M$, et al. Nutrition knowledge among young Finnish endurance athletes and their coaches. Int J Sport Nutr Exerc Metab. 2018;28:522-7.

24. Jovanov P, Đorđić V, Obradović B, et al. Prevalence, knowledge and attitudes towards using sports supplements among young athletes. J Int Soc Sports Nutr. 2019;16:27.
25. Wang X, Chen Y, Liu Y, et al. Reporting items for systematic reviews and meta-analyses of acupuncture: the prisma for acupuncture checklist. BMC Complement Altern Med. 2019;19:208.

26. Fernández-Lázaro D, Mielgo-Ayuso J, Seco Calvo J, et al. Modulation of exercise-induced muscle damage, inflammation, and oxidative markers by curcumin supplementation in a physically active population: a systematic review. Nutrients. 2020;12.

27. Law MS, D. Pollock, N. Letts, L. Bosch, J. Westmorland, M.: Guidelines for critical review form - quantitative studies 1998. Hamilton, ON, Canada: McMaster University; 2008(Series Editor).

28. Mero AA, Hirvonen P, Saarela J, et al. Effect of sodium bicarbonate and beta-alanine supplementation on maximal sprint swimming. J Int Soc Sports Nutr. 2013;10:52.

29. Oliveira LF, de Salles PV, Nemezio K, et al. Chronic lactate supplementation does not improve blood buffering capacity and repeated high-intensity exercise. Scand J Med Sci Sports. 2017;27:1231-9.

30. Correia-Oliveira CR, Lopes-Silva JP, Bertuzzi R, et al. Acidosis, but not alkalosis, affects anaerobic metabolism and performance in a 4-km time trial. Med Sci Sports Exerc. 2017;49:1899-910.

31. Thomas C, Delfour-Peyrethon R, Bishop DJ, et al. Effects of pre-exercise alkalosis on the decrease in vo2 at the end of all-out exercise. Eur J Appl Physiol. 2016;116:85-95.

32. Zabala M, Peinado AB, Calderón FJ, et al. Bicarbonate ingestion has no ergogenic effect on consecutive all out sprint tests in bmx elite cyclists. Eur J Appl Physiol. 2011;111:3127-34.

33. Peinado $A B$, Holgado $D$, Luque-Casado $A$, et al. Effect of induced alkalosis on performance during a field-simulated bmx cycling competition. J Sci Med Sport. 2019;22:335-41.

34. Joyce $S$, Minahan C, Anderson M, et al. Acute and chronic loading of sodium bicarbonate in highly trained swimmers. Eur J Appl Physiol. 2012; 112:461-9.

35. De Araujo Dias GF, Eira Silva VD, Painelli VDS, et al.: (in)consistencies in responses to sodium bicarbonate supplementation: A randomised, repeated measures, counterbalanced and double-blind study. PLoS One 2015, 10.

36. Freis $T$, Hecksteden A, Such $U$, et al. Effect of sodium bicarbonate on prolonged running performance: a randomized, double-blind, cross-over study. PLoS One. 2017;12:e0182158.

37. Higgins JP, Thompson SG, Deeks JJ, et al. Measuring inconsistency in metaanalyses. Bmj. 2003;327:557-60.

38. Cohen J. A power primer. Psychol Bull. 1992;112:155-9.

39. Mündel T: Sodium bicarbonate ingestion improves repeated high-intensity cycling performance in the heat. Temperature (Austin, Tex) 2018, 5:343-347.

40. Carr BM, Webster MJ, Boyd JC, et al. Sodium bicarbonate supplementation improves hypertrophy-type resistance exercise performance. Eur J Appl Physiol. 2013;113:743-52.

41. Saunders B, Sale C, Harris RC, et al. Sodium bicarbonate and high-intensitycycling capacity: variability in responses. Int J Sports Physiol Perform. 2014;9: 627-32.

42. Hobson RM, Harris RC, Martin D, et al. Effect of sodium bicarbonate supplementation on 2000-m rowing performance. Int J Sports Physiol Perform. 2014;9:139-44.

43. Siegler JC, Gleadall-Siddall DO. Sodium bicarbonate ingestion and repeated swim sprint performance. J Strength Cond Res. 2010;24:3105-11.

44. Deb SK, Gough LA, Sparks SA, et al. Determinants of curvature constant (w') of the power duration relationship under normoxia and hypoxia: the effect of pre-exercise alkalosis. Eur J Appl Physiol. 2017;117:901-12.

45. Smith $\mathrm{Gl}$, Jeukendrup AE, Ball D. The effect of sodium acetate ingestion on the metabolic response to prolonged moderate-intensity exercise in humans. Int J Sport Nutr Exerc Metab. 2013;23:357-68.

46. Mueller SM, Gehrig SM, Frese S, et al. Multiday acute sodium bicarbonate intake improves endurance capacity and reduces acidosis in men. J Int Soc Sport Nutr. 2013;10:16

47. Egger F, Meyer T, Such U, et al. Effects of sodium bicarbonate on highintensity endurance performance in cyclists: a double-blind, randomized cross-over trial. PLoS One. 2014;9.

48. Macutkiewicz D, Sunderland C. Sodium bicarbonate supplementation does not improve elite women's team sport running or field hockey skill performance. Physiol Rep. 2018;6:e13818.

49. Wu CL, Shih MC, Yang CC, et al. Sodium bicarbonate supplementation prevents skilled tennis performance decline after a simulated match. J Int Soc Sport Nutr. 2010;7:33. 
50. McNaughton LR, Siegler J, Midgley A. Ergogenic effects of sodium bicarbonate. Curr Sports Med Rep. 2008;7:230-6.

51. Peart DJ, Siegler JC, Vince RV. Practical recommendations for coaches and athletes: a meta-analysis of sodium bicarbonate use for athletic performance. J Strength Cond Res. 2012;26:1975-83.

52. Lopes-Silva JP, Reale R, Franchini E. Acute and chronic effect of sodium bicarbonate ingestion on Wingate test performance: a systematic review and meta-analysis. J Sports Sci. 2019;37:762-71.

53. Lopes-Silva JP, Choo HC, Franchini E, et al. Isolated ingestion of caffeine and sodium bicarbonate on repeated sprint performance: a systematic review and meta-analysis. J Sci Med Sport. 2019;22:962-72.

54. Gough LA, Rimmer S, Sparks SA, et al. Post-exercise supplementation of sodium bicarbonate improves acid base balance recovery and subsequent high-intensity boxing specific performance. Front Nutr. 2019;6:155.

55. Durkalec-Michalski K, Nowaczyk PM, Adrian J, et al. The influence of progressive-chronic and acute sodium bicarbonate supplementation on anaerobic power and specific performance in team sports: a randomized, double-blind, placebo-controlled crossover study. Nutrition \& Metabolism. 2020:17:1-15.

56. Edge J, Bishop D, and Goodman C: Effects of chronic nahco3 ingestion during interval training on changes to muscle buffer capacity, metabolism, and short-term endurance performance. J Appl Physiol (1985) 2006, 101: 918-25.

57. Kahle LE, Kelly PV, Eliot KA, et al. Acute sodium bicarbonate loading has negligible effects on resting and exercise blood pressure but causes gastrointestinal distress. Nutr Res. 2013;33:479-86.

58. Siegler JC, Marshall PW, Bray J, et al. Sodium bicarbonate supplementation and ingestion timing: does it matter? J Strength Cond Res. 2012;26:1953-8.

59. De Franca E, Xavier AP, Dias IR, et al. Fractionated sodium bicarbonate coingestion with carbohydrate increase performance without gastrointestinal discomfort. Rbne. 2015;9:437-46.

60. Hilton NP, Leach NK, Craig MM, et al. Enteric-coated sodium bicarbonate attenuates gastrointestinal side-effects. International Journal of Sport Nutrition \& Exercise Metabolism. 2020;30:62-8.

61. Grgic J, Garofolini A, Pickering C, et al. Isolated effects of caffeine and sodium bicarbonate ingestion on performance in the yo-yo test: a systematic review and meta-analysis. J Sci Med Sport. 2020;23:41-7.

62. Ferreira LHB, Smolarek AC, Chilibeck PD, et al.: High doses of sodium bicarbonate increase lactate levels and delay exhaustion in a cycling performance test. Nutrition (Burbank, Los Angeles County, Calif) 2019, 60: 94-99.

\section{Publisher's Note}

Springer Nature remains neutral with regard to jurisdictional claims in published maps and institutional affiliations.

Ready to submit your research? Choose BMC and benefit from:

- fast, convenient online submission

- thorough peer review by experienced researchers in your field

- rapid publication on acceptance

- support for research data, including large and complex data types

- gold Open Access which fosters wider collaboration and increased citations

- maximum visibility for your research: over $100 \mathrm{M}$ website views per year

At $\mathrm{BMC}$, research is always in progress.

Learn more biomedcentral.com/submissions 